\title{
AMALi - the Airborne Mobile Aerosol Lidar for Arctic research
}

\author{
I. S. Stachlewska ${ }^{1,2}$, R. Neuber ${ }^{1}$, A. Lampert ${ }^{1}$, C. Ritter ${ }^{1}$, and G. Wehrle ${ }^{1,3}$ \\ ${ }^{1}$ Alfred Wegener Institute for Polar and Marine Research, Telegrafenberg A43, 14473 Potsdam, Germany \\ ${ }^{2}$ Institute of Geophysics, Faculty of Physics, University of Warsaw, Pasteura 7, 02-093 Warsaw, Poland \\ ${ }^{3}$ Laboratory of Atmospheric Chemistry, Paul Scherrer Institut, 5232 Villigen PSI, Switzerland
}

Received: 30 June 2009 - Published in Atmos. Chem. Phys. Discuss.: 10 September 2009

Revised: 18 March 2010 - Accepted: 25 March 2010 - Published: 29 March 2010

\begin{abstract}
The Airborne Mobile Aerosol Lidar (AMALi) is an instrument developed at the Alfred Wegener Institute for Polar and Marine Research for reliable operation under the challenging weather conditions at the Earth's polar regions. Since 2003 the AMALi has been successfully deployed for measurements in ground-based installation and zenith- or nadir-pointing airborne configurations during several scientific campaigns in the Arctic. The lidar provides backscatter profiles at two wavelengths $(355 / 532 \mathrm{~nm}$ or $1064 / 532 \mathrm{~nm})$ together with the linear depolarization at $532 \mathrm{~nm}$, from which aerosol and cloud properties can be derived. This paper presents the characteristics and capabilities of the AMALi system and gives examples of its usage for airborne and ground-based operations in the Arctic. As this backscatter lidar normally does not operate in aerosol-free layers special evaluation schemes are discussed, the nadir-pointing iterative inversion for the case of an unknown boundary condition and the two-stream approach for the extinction profile calculation if a second lidar system probes the same air mass. Also an intercomparison of the AMALi system with an established ground-based Koldewey Aerosol Raman Lidar (KARL) is given.
\end{abstract}

\section{Introduction}

Backscatter airborne lidar systems have been applied to aerosol studies since the eighties, e.g. the Aerosol Lidar EXperiment (ALEX), developed at the German Aerospace Center (DLR) based on the elastic detection at $355 \mathrm{~nm}, 532 \mathrm{~nm}$, $1064 \mathrm{~nm}$ (Moerl et al., 1981; Renger et al., 1997) or the

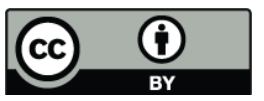

Correspondence to: R. Neuber (roland.neuber@awi.de)
French airborne lidar LEANDRE measuring the elastic signals at $532 \mathrm{~nm}$ and depolarization at $1064 \mathrm{~nm}$ (Flamant et al., 2000). With time, significantly smaller, portable systems with modular configurations appeared on the scene. The Lidar Aerosol UltraViolet Aeroporte (LAUVA), developed at the CEA/CNRS, France is an eye-safe system based on $355 \mathrm{~nm}$ wavelength which can be installed on an ultralight airplane or a balloon for atmospheric applications (Chazette et al., 2007, 2008) and canopy measurements (Cuesta et al., 2009). The POrtable LIdar System (POLIS) developed at the Meteorological Institute at the University of Munich (MIM LMU) in collaboration with the Ground Truth Center Oberbayern (GTCO), Germany, has a modular design available for three configurations: two backscatter signals at $355 \mathrm{~nm}$ and $532 \mathrm{~nm}$, or backscatter at $355 \mathrm{~nm}$ and its Raman nitrogen-shifted signal at $387 \mathrm{~nm}$, or backscatter and depolarization at $532 \mathrm{~nm}$ or $355 \mathrm{~nm}$ (Heese et al., 2002, 2004). Airborne lidars have been applied to study clouds, e.g. the Cloud Physics Lidar (CPL), developed at NASA based on $355 \mathrm{~nm}, 532 \mathrm{~nm}, 1064 \mathrm{~nm}$ elastic detection with depolarization measurements at $1064 \mathrm{~nm}$ (McGill et al., 2002, 2003).

One of the primary objectives of the Atmospheric Division at the Alfred Wegener Institute for Polar and Marine Research (AWI), Research Unit Potsdam, is to improve the understanding of the direct and indirect effects of Arctic aerosol and clouds on the climate system. The full assessment can only be accomplished by collaborative studies of Arctic aerosol-cloud-climate interactions by combining the experimental data of aerosol and cloud properties obtained from local observatories, field campaigns, and satellite measurements (Treffeisen et al., 2004; Yamanouchi et al., 2005) applied together with a regional climate model, especially designed for the Arctic (Dethloff et al., 1996; Rinke et al., 2004). The main focus of the lidar group at the AWI Potsdam Research Unit is to provide the observations of Arctic aerosol

Published by Copernicus Publications on behalf of the European Geosciences Union. 
and clouds necessary for the modeling activities, and to investigate the properties of the Arctic atmosphere via designing, building and operating lidar systems suitable for measurements in challenging Arctic conditions. One of these, the Airborne Mobile Aerosol Lidar (AMALi) was developed in 2003 (Stachlewska et al., 2004) and has been successfully operating, integrated on board the AWI's Polar 2 research aircraft, during several international campaigns. Since 2009, the AMALi is also certified for operation on board the AWI's Polar 5, a Basler BT-67 research aircraft. In 2006, the AMALi was modified. Its modular design allowed to change the detection wavelengths from the first and the second Nd:YAG harmonics to the second and third harmonics which promised an improved capability for detecting the small Arctic Haze aerosol particles. The two exchangable configurations are called the IRVIS configuration (based on $1064 \mathrm{~nm}$ and $532 \mathrm{~nm}$ ) and the UVVIS configuration (based on $355 \mathrm{~nm}$ and $532 \mathrm{~nm}$ ). Additionally, after the modification of the AWI's Polar 2 and Polar 5 aircraft (opening on the roof), the option of reading out the signals in both analog and photon counting mode was included and airborne operation of the AMALi not only in the nadir-pointing configuration but also in the zenith-pointing configuration became possible. Data obtained from zenith-pointing airborne measurements have a potential to be used in the future for validation of vertical profiles of aerosol and cloud backscatter and depolarization of the Cloud-Aerosol LIdar with Orthogonal Polarization (CALIOP) on board of the Cloud-Aerosol Lidar and Infrared Pathfinder Satellite (CALIPSO; Winker et al., 2007). Furthermore, it is possible to investigate aerosol layers in the free troposphere as well as midlevel and high cirrus clouds for flights at low altitude.

Before the Arctic campaigns took place, the system was validated and tested during January-April 2004 and AugustDecember 2006 by performing ground based investigations of the diurnal boundary layer cycle from the AWI's Lidar Laboratory in Potsdam. Additionally, robust construction and trouble-free operation of the AMALi was proved during the lidar test flights in April 2004, March 2005 and July 2006. This allowed for an airborne investigation of the sea-land aerosol gradients over the north-western coastline offshore Bremerhaven. Additionally, after the implementation of the UVVIS configuration the AMALi was operated next to another AWI lidar, the COMpact Cloud and Aerosol Lidar (COMCAL; Immler et al., 2006) in vicinity of Bremerhaven, where both lidars observed the same boundary layer and cirrus structures.

The lidar group performed high quality airborne observations of various atmospheric events with the AMALi system operated in nadir-pointing IRVIS configuration during the Arctic Study of Aerosol, Clouds and Radiation ASTAR 2004 and the Svalbard Experiment SVALEX 2005 campaigns in the Arctic. After the modification, the AMALi was operated in alternatively nadir- or zenith-pointing UVVIS configuration during the ASTAR 2007 and the Pan-Arctic Measure- ments and Arctic Regional Climate Model Intercomparison PAM-ARCMIP 2009 campaigns.

The campaigns resulted in several aerosol and cloud studies involving the AMALi system. The attenuated backscatter data obtained by another ground based lidar and the AMALi overflying it were combined to obtain profiles of extinction and backscatter coefficient as well as lidar ratio profiles. This was done using the two-stream approach which was compared with the corresponding Raman lidar retrievals (Stachlewska and Ritter, 2010). For the two-stream retrievals a proper selection of the signals from both lidars which must be colocated in time and space is crucial (Ritter et al., 2006). The results obtained using the two-stream approach were compared with the optical depth obtained by sunphotometer and radiosonding profiles and interpreted as clean and polluted Arctic conditions by the microphysical parameters retrieved from the Raman lidar and backward trajectories calculated with the HYSPLIT and FLEXPART models (Stachlewska et al., 2005).

The atmospheric dynamics were investigated using the airborne lidar combined with trajectory models. Aerosol load distributions in the lower troposphere measured by the AMALi around Svalbard during intense easterly winds were interpreted with the ECMWF model (Stachlewska and Dörnbrack, 2006a) and further modelling of the extent of the local dust plume was simulated with the EULAG model (Dörnbrack et al., 2010).

Observations of boundary layer, mixed-phase and multilayer Arctic clouds were interpreted using meteorology. The influence of the atmospheric state was found to be substantial, e.g. even in the free troposphere, multi-layer clouds formed by a disturbance of the wind field near Svalbard (Lampert et al., 2010). Mixed-phase clouds in the lower troposphere were observed during airborne AMALi measurements and allowed to guide the aircraft into areas within these clouds for measuring in situ their microphysical parameters (Stachlewska, 2006b; Stachlewska et al., 2006c; Gayet et al., 2007). The boundary layer mixed-phase clouds observed by airborne lidar, radiation and in situ instrumentation were completely frozen at the intersection of two different air masses in a small band along the air mass mixing zone (Richter et al., 2008). The cloud phase of boundary layer mixed-phase clouds was identified based on spectral radiation, in situ and airborne lidar measurements. In the predominantly liquid cloud top layer also a much smaller amount of ice crystals was found (Ehrlich et al., 2008).

Measurements and simulations of the properties of a subvisible Arctic ice cloud and its impact on the radiation budget were performed. The combined lidar, in situ and radiation instruments evidenced an ice cloud of very low particle concentration. Some large ice crystals and more small spherical ice crystals were observed. The radiative impact of the cloud was calculated as $-3.2 \mathrm{~W} \mathrm{~m}^{-2}$ in the solar wavelength range and $+2.8 \mathrm{~W} \mathrm{~m}^{-2}$ in the terrestrial wavelength range (Lampert et al., 2009). 


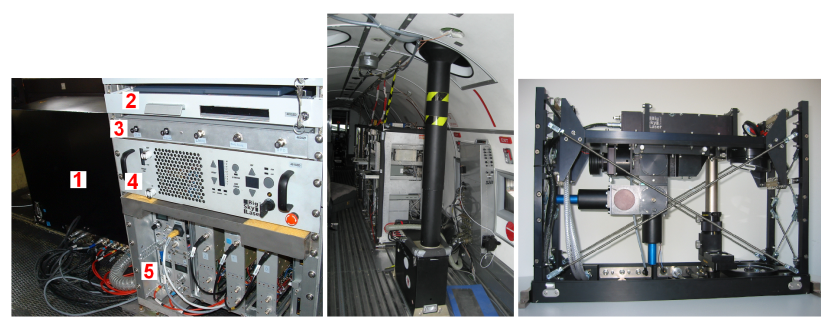

Fig. 1. The AMALi in nadir-pointing airborne configuration on board the Polar 2 aircraft (left) and in zenith-pointing configuration on board the Polar 5 (middle). The main AMALi elements are the optical assembly (1) with its interior on the right photo, laptop (2), safety breaker box (3), laser control and cooling unit (4), and transient recorders (5).

This paper gives a detailed description of the AMALi lidar and its performance, as well as discusses the routine evaluation schemes applied to the airborne data.

\section{Instrument description}

The AMALi is a small, robust and easy to transport lidar used for remote high resolution detection of the vertical and horizontal extent of the tropospheric aerosol load and clouds at two wavelengths and a depolarization at one of them, simultaneously. The lidar is mounted in two small and portable modules. The transmitting and receiving subsystems are mounted inside a small $(70 \times 50 \times 25 \mathrm{~cm})$, light weight $(45 \mathrm{~kg})$ optical assembly (Fig. 1). The second module comprising the laser control and cooling unit, the laptop, the transient recorders and the safety breaker box is mounted in a standard size rack $(55 \times 50 \times 60 \mathrm{~cm})$. The optical assembly was specially designed by the lidar group of AWI Potsdam in a way to assure the lowest weight, space and energy consumption for the operation on board the Dornier Do 228 research aircraft Polar 2. The optical assembly was manufactured by Steingross Feinmechanik, Berlin.

All vital lidar parts, i.e. the laser head, the directing optics, the receiving mirror and the detector block with its optoelectronic elements are mounted onto the same optical bench inside the optical assembly (Fig. 1, right). The single-opticalbench design simplifies the adjustment of all optical elements and ensures reliable and trouble-free utilization during campaigns, without the need of readjustment. The optical bench itself hangs on anti-shock springs attached to four posts. The springs eliminate vibrations of the optical bench during the operation on board the aircraft. The weight and position of all elements on the optical bench is chosen in a way that the center of gravity results in the middle of the optical assembly. The four posts together with a base plate form a massive construction providing mechanical stability to the system. During measurements the optical assembly is covered with a sheet metal box capturing any scattered laser light and
Table 1. Technical specifications of the CRF-200, Big Sky Laser, Quantel, Montana, USA. This laser can be used in the AMALi lidar in the IRVIS or the UVVIS configuration.

\begin{tabular}{|c|c|c|}
\hline Parameter [Unit] & Value & Comment \\
\hline $\begin{array}{l}\text { Maximum altitude for } \\
\text { safe operation }[\mathrm{m}]\end{array}$ & 3000 & \\
\hline Beam diameter [mm] & 6 & \\
\hline Pulse Duration [ns] & 11.38 & \\
\hline $\begin{array}{l}\text { Beam divergence [mrad] } \\
\text { (86.5\% energy) }\end{array}$ & 2.59 & \\
\hline Pulse repetition frequency $[\mathrm{Hz}]$ & 15 & \\
\hline \multicolumn{3}{|c|}{ The IRVIS configuration 2003-2006 } \\
\hline Pulse energy at $1064 \mathrm{~nm}[\mathrm{~mJ}]$ & 60 & \\
\hline Pulse energy at $532 \mathrm{~nm}[\mathrm{~mJ}]$ & 120 & \\
\hline \multicolumn{3}{|c|}{ The UVVIS configuration 2006-2009 } \\
\hline $\begin{array}{l}\text { Pulse energy at } 1064 \mathrm{~nm} \\
\text { (residual) [mJ]] }\end{array}$ & 45 & $\begin{array}{l}\text { absorbed by ceramic } \\
\text { glass absorber }\end{array}$ \\
\hline Pulse energy at $532 \mathrm{~nm}[\mathrm{~mJ}]$ & 94 & \\
\hline Pulse energy at $355 \mathrm{~nm}[\mathrm{~mJ}]$ & 15 & \\
\hline
\end{tabular}

thereby ensuring the safety of pilots and operators, as well as protecting the detection system from stray light and background radiation.

The design of AMALi allows vertical measurements in nadir- and zenith-pointing configuration on board the Polar 2 (Fig. 1, left) and the Polar 5 (Fig. 1, middle). When it is operated at the ground or integrated in a car/ship measurements are taken vertically upward. Horizontal observations are possible for the optical assembly lying on a side. The assembly is small and light enough to be installed in an elevation/azimuth moving platform to perform scans.

\subsection{Transmitter subsystem}

As a transmitter, a custom designed small rugged and easy to handle flashlamp pumped Nd:YAG pulsed laser (CRF-200, Big Sky Quantel, Montana, USA) is used (Table 1). It is provided with a portable power supply and cooling unit which is small $(12 \times 45 \times 48 \mathrm{~cm})$ and light weight $(3 \mathrm{~kg})$. The laser, equipped with frequency doubler and tripler crystals, emits simultaneously two wavelengths. The double wavelength backscatter lidar scheme was chosen for its conceptual simpleness ensuring an easy and trouble-free operation during field campaigns under tough Arctic weather conditions. The laser is cooled with an ethylene glycol and water 1:1 solution to ensure that the liquid will not freeze while the laser is operating in Arctic or at high altitudes. The maximum nominal operation height for the laser given by the manufacturer is $3 \mathrm{~km}$.

In the years 2003-2006 the IRVIS configuration with the two first harmonics was used, i.e. $1064 \mathrm{~nm}$ (elliptical polarization) and $532 \mathrm{~nm}$ (linear vertical polarization) 


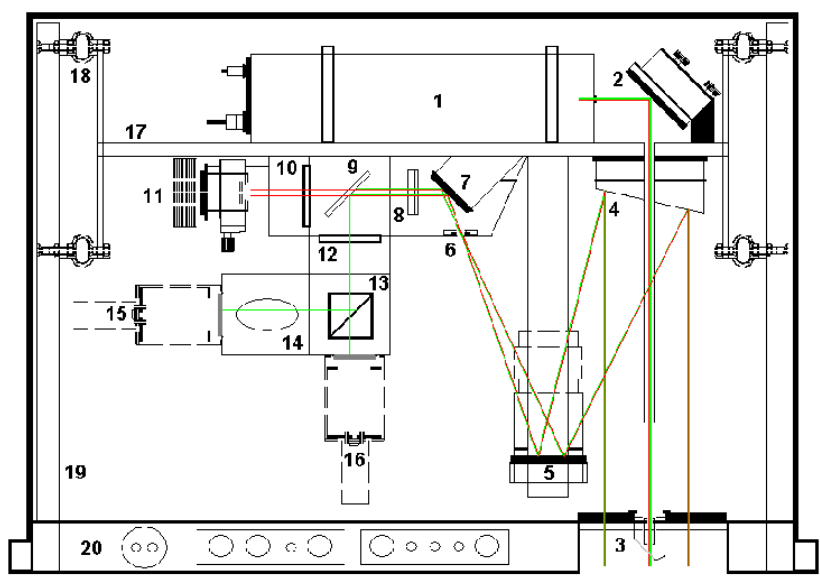

Fig. 2. The AMALi optical assembly with schematically drawn ray-tracking at $532 \mathrm{~nm}$ (green) and $1064 \mathrm{~nm}$ (red). The numbers indicate the main components of the IRVIS configuration in the assembly; 1 . laser head 2. directing mirror with piezo motor 3. window with Brewster's angle 4. off-axis parabolic mirror 5. first folding mirror 6. pinhole 7. second folding mirror 8. achromatic lens 9. beam splitter 10. interference filter for $1064 \mathrm{~nm}$ channel 11. APD for $1064 \mathrm{~nm}$ detection 12. interference filter for $532 \mathrm{~nm}$ channel 13. polarizing cube 14. thin film polarizing filter 15. PMT for perpendicular $532 \mathrm{~nm}$ detection 16. PMT for parallel $532 \mathrm{~nm}$ detection 17. optical bench 18. springs 19. posts 20. base plate. In the UVVIS configuration the IR detection channel is replaced with the UV detection channel comprising interference filter and PMT for $355 \mathrm{~nm}$ detection. The waveplate and Glan-Taylor polarizer are integrated in the tube guiding the laser pulses through the perforation of the receiving mirror.

wavelengths, with $11 \mathrm{~ns}$ short light pulses with energies of $60 \mathrm{~mJ}$ and $120 \mathrm{~mJ}$, respectively, emitted with the pulse repetition rate of $15 \mathrm{~Hz}$. At $532 \mathrm{~nm}$ the laser beam divergence $\delta$ is $2.6 \mathrm{mrad}$ and the diameter of the laser beam at the laser head $g_{0}$ is $6 \mathrm{~mm}$. By the end of 2006 mainly the UVVIS configuration with the second and third harmonics was used, i.e. linearly polarized $532 \mathrm{~nm}$ and linearly polarized $355 \mathrm{~nm}$ wavelengths, with $11 \mathrm{~ns}$ short light pulses with energies of $94 \mathrm{~mJ}$ and $15 \mathrm{~mJ}$, respectively, emitted with the pulse repetition rate of $15 \mathrm{~Hz}$. The residual energy of the basic wavelength of $1064 \mathrm{~nm}$ (less than $45 \mathrm{~mJ}$ ) is absorbed in the housing box by a white ceramic glass absorber material called Macor. The field of view in the UV is spherical as in VIS. The exact divergence of the UV pulse was estimated by the manufacturer as $1.5-2.5 \mathrm{mrad}$, based on the measurement of the divergence for the $532 \mathrm{~nm}$.

After the integration of the third harmonic generator crystal the linear polarization at $532 \mathrm{~nm}$ was found to be poor (above 90\%). Therefore, additionally to the dual wavelength waveplate (CVI Laser, USA) which rotates the polarization of the $532 \mathrm{~nm}$ wavelength to match the polarization of the $355 \mathrm{~nm}$ wavelength, also a Glan Taylor polarizer (OFR, USA) was included in the optical assembly in the tube which is guiding the laser pulses through a hole in the telescope mirror. The Glan-Taylor prism acts as a polarization filter, passing only linear polarized light into the atmosphere. The perpendicular polarization is absorbed in the tube. The waveplate was adjusted by maximizing the signal at the $532 \mathrm{~nm}$ parallel detector and minimizing the signal at the $532 \mathrm{~nm}$ perpendicular detector. The Glan Taylor polarizer was then adjusted to minimize the signal at the $532 \mathrm{~nm}$ perpendicular detector. Although the degree of linear polarization of the transmitted beam was not measured after the adjustment, we expect it to be high due to the extinction ratio of the Glen Taylor polarizer of $5 \times 10^{-5}$.

\subsection{Receiver subsystem}

The optical layout of the receiver is composed of all signal collecting parts attached to the bottom of the optical bench. As for backscatter lidars, it is not necessary to use a primary mirror that is completely rotationally symmetric, we used an off-axis primary mirror which was cut off a larger parabolic and rotationally symmetric mirror in a way that the focal point of it is outside the mirror and not in the center of the mirror. If we had used a symmetric parabolic mirror we would have had astigmatism problems. The off-axis mirror itself has a rotationally asymmetric aperture, but the aperture stop (pinhole) is rotationally symmetric. This choice assures a diffraction limited optical system without astigmatisms and at the same time it allows the lidar dimensions to remain small (size and weight) due to a compact folded optical design. Hence, the use of the off-axis configuration frees the lidar from astigmatism, while the use of the aspherical, parabolic mirror avoids spherical aberrations.

The backscattered light is collected with the off-axis parabolic mirror coated with protected silver coating (OAP 18-05-04Q, Space Optics Research Labs, USA). The mirror diameter is $10.2 \mathrm{~cm}$ and the clear aperture $9.9 \mathrm{~cm}$. The focal length is $48.0 \mathrm{~cm}$, while the off-axis distance is $12.7 \mathrm{~cm}$. The accuracy of the mirror's surface is high. The mirror's roughness is low with the figure of $\lambda / 10$ wave-peak to valley (measured at $632.8 \mathrm{~nm}$ over $99 \%$ of the clear aperture). The mirror's shape is good with a slope of $\lambda / 8$ waves per inch at $90 \%$. The high reflective (near-UV, VIS and near-IR spectra) silver coating is a soft chemical surface with a low durability, damage threshold and likely oxidation tarnishing. Hence, the silver layer is additionally over-coated with a hard, single, dielectric layer of half-wavelength optical thickness at $550 \mathrm{~nm}$. This protective film arrests oxidation, helps maintain high reflectance, improves the minor abrasions and tarnish resistance, while only marginally affecting the optical properties.

The off-axis primary mirror is mounted onto the optical bench (Fig. 2) in a way that the laser light is sent through its central perforation of $3.1 \mathrm{~cm}$ diameter. The planar secondary mirror is mounted on a rod which is also attached to the optical bench. Similarly, the detector block with its optoelectronic elements, each placed inside one of the detection 
module-boxes, is also attached to the optical bench. The light collected with the primary mirror is redirected by the first folding mirror onto a $1.5 \mathrm{~mm}$ pinhole on the detector block. Such a choice of pinhole size together with the parameters of the primary mirror result in $3.1 \mathrm{mrad}$ field of view, necessary for the detection of the complete return signal of the strongly divergent laser beam. After passing the pinhole the light is redirected using the second plane folding mirror to an achromatic lens used to produce parallel rays while avoiding chromatic aberration.

In the IRVIS configuration signals of both wavelengths are separated into two different detection channels using a dichroic mirror inclined at $45^{\circ}$ which transmits the $1064 \mathrm{~nm}$ and reflected the $532 \mathrm{~nm}$ signal. In the UVVIS configuration, a dichroic mirror which transmits the $355 \mathrm{~nm}$ and reflects the $532 \mathrm{~nm}$ signal is used. For both configurations, the latter wavelength is additionally separated into its parallel and perpendicular component using a polarising cube beam splitter provided by Laseroptik Garbsen, Germany.

In front of the photo-detectors interference filters (IF) are placed to reduce the background daylight radiation. For the IR channel we used a $1.0 \mathrm{~nm}$ wide IF centred around $1064 \mathrm{~nm}$ and for both VIS channels a $0.15 \mathrm{~nm}$ IF centred around $532 \mathrm{~nm}$. For the UV channel, an IF of $1.0 \mathrm{~nm}$ bandwidth centred around $355 \mathrm{~nm}$ was employed. The IF filters for $355 \mathrm{~nm}$ and $532 \mathrm{~nm}$ are provided by Barr, USA, and Andover Corporation, USA, respectively.

The less intense, perpendicular component of the $532 \mathrm{~nm}$ channel is additionally filtered for cross-talk using a thin film polarising filter at a $56^{\circ}$ angle. For the final installation the position of the polarizing cube was adjusted in a laboratory experiment and fixed in the optimal position to minimize the cross-talk of the two $532 \mathrm{~nm}$ detection channels. The adjustment was performed in dark conditions using the $\mathrm{Nd}$ :YAG laser itself. The energy of the laser beam was measured before it entered the detection block unit, then consecutively after the beamsplitter, the interference filter, the polarizing cube on the parallel and the perpendicular channels, and finally after the thin film polarizing filter on the perpendicular channel. Each optical element was successively adjusted and fixed. The cross-talk contribution of the parallel on the perpendicular channel is $10^{-3} \%$, further reduced to $10^{-6} \%$ by the thin film polarizing filter.

For the detection of the $1064 \mathrm{~nm}$ channel a Peltier cooled Si Avalanche Photo-Diode (APD) was used, and Hamamatsu R7400 photomultipliers (PMT) for the detection of the $355 \mathrm{~nm}$ channel and the two $532 \mathrm{~nm}$ channels for the parallel and perpendicular component.

Due to the strongly limited range of the nadir-pointing airborne signals a high peak of the ground return occurs. However, in the IRVIS configuration, the use of absorptive neutral density filters to reduce the intensity of the incoming light was not necessary for analog detection. In the UVVIS configuration with the more sensitive photon counting mode, neutral density filters were integrated in front of the PMTs for the $532 \mathrm{~nm}$ parallel and the $355 \mathrm{~nm}$ signal to avoid saturation of the detectors. The optical depths of 1.0 and 0.8 , respectively, were chosen in a way that the output voltage of the PMTs was not at the limit for more than the first $50 \mathrm{~m}$ of the lidar signal return.

\subsubsection{Detection range limitation}

Despite its relatively small size, AMALi in a ground based configuration is powerful enough to cover the range up to the tropopause level but for airborne measurements its range is limited. The detection range in nadir-pointing airborne measurement is limited on the one hand by the maximum nominal operation height for the laser (up to $3 \mathrm{~km}$ ), and the maximum allowed flight altitude without using oxygen masks by the pilots and scientific crew (up to $3 \mathrm{~km}$ for the installation in the Polar 2 and Polar 5 aircraft). On the other hand the minimum flight altitude is imposed by eye-safety constraints, i.e. $2.4 \mathrm{~km}$ for the IRVIS configuration, $2.1 \mathrm{~km}$ for the UVVIS configuration (Appendix A). In zenith-pointing airborne configuration, signals are limited on the one hand by the maximum nominal operation height for the laser and the allowed flight altitude (up to $3 \mathrm{~km}$ ). On the other hand by the maximum detection range which depends on the required signal-to-noise ratio (SNR), thus the integration time, which depends on the altitude of the structures of interest, e.g. for zenith-pointing cloud observations in $4 \mathrm{~km}$ altitude, an integration time of $15 \mathrm{~s}$ is used.

For the AMALi a SNR of 15 leads to errors of $5 \%$ in the determination of the backscatter ratio, which is acceptable. The SNR does not vary in time as measurement parameters are not modified, i.e. the laser runs stable and the high voltage applied to the PMTs is kept unchanged. Hence, both the signal strength and the SNR are very similar from case to case. At a SNR of 15 or higher the total error in the retrieval of the backscatter coefficient is not dominated by the noise but it is dependent on the choice of the the boundary condition value, the precision of the atmospheric density profile and the choice of the lidar ratio. When the boundary condition (with the lidar constant $C$ known) can be obtained using the iterative method described in this paper and the atmospheric density profile is retrieved from radiosonde launch, the choice of the unknown lidar ratio will be the dominant source of errors for the AMALi retrievals.

\subsubsection{Overlap}

Considering the laser pulse energy, the pulse repetition rate, the laser beam divergence $\delta$, the beam diameter at the laser head $g_{0}$, and the primary mirror diameter $T$ we chose the pinhole diameter $s$ with the constraint to achieve the lowest possible geometric compression $\xi$ (Sect. 3) with the lowest integration times for the weakest detection channel during the airborne nadir-pointing operation (i.e. perpendicular $532 \mathrm{~nm}$ ). To achive this we integrated an overlap-adjustment 
module just after the laser head. A planar mirror which is highly reflective for the two relevant wavelengths is mounted onto a piezo stepper motor at an angle of approximately $45^{\circ}$. This mirror redirects the laser beam through the opening in the optical bench on which the laser head is resting and sends it almost parallel to the optical axis of the receiving telescope mirror. The distance between the telescope optical axis and the laser beam axis $d_{0}$ is set to $7.5 \mathrm{~mm}$. Such construction allows fine adjustments of the overlap $\xi$ between the emitted laser beam and the telescope's mirror field of view $\varphi$. The complete overlap at a full field of view calculated analytically for the small $\theta, \varphi$ and $\delta$ angles approximation, follows $\xi=\frac{2 d_{0}+T+g_{0}}{2 \theta+\varphi-\delta}$. For AMALi the overlap is completed at a distance $\xi_{\max }$ of $235 \mathrm{~m}$, when the laser beam is not inclined $(\theta=0)$. Inclination of the laser beam to the maximum applicable inclination angle $\left(\theta=\frac{\varphi-\delta}{2}\right)$ of $0.27 \mathrm{mrad}$ results in $\xi_{\text {min }}$ of $155 \mathrm{~m}$.

\subsection{Data acquisition subsystem}

A single laptop computer (TOSHIBA, $2 \mathrm{GHz}, \mathrm{CPU} 30 \mathrm{~GB}$, HD 256 MB RAM, USB-RS 232) fully controls the laser, transient recorders, detectors, and data acquisition, including storage, processing, quick-look evaluation and display programs utilizing LabVIEW software. A transient recorder (TR20-80, LICEL GmbH, Berlin) combining an $\mathrm{A} / \mathrm{D}$ converter $(12$ bit at $20 \mathrm{MHz}$ ) for analog detection with a $250 \mathrm{MHz}$ fast photon counting system are used. An ethernet control module using a TCP/IP protocol allows remote control and data transfer for both photon counting and analog recorders. Transient recorders register the pulses with a maximum sampling rate of $20 \mathrm{MHz}$ corresponding to a height resolution of $7.5 \mathrm{~m}$ for one range bin.

In the ground-based configuration the standard groundbased LICEL GmbH data acquisition software is employed. Here, each lidar return signal from each channel is stored separately at a minimum time average of $1 \mathrm{~s}$. With this standard software the profiles up to the tropopause level can be easily obtained. For the airborne configurations a custom designed airborne LICEL GmbH software is employed. Here, typically each new lidar return signal from each of the three channels is appended and stored with a temporal integration of $1 \mathrm{~s}$ per profile in a block file of $2 \mathrm{~min}$. However, a resolution as fine as a single-shot acquisition is also possible.

For nadir-pointing measurements the length of collected signal was limited to 1000 range bins $(7.5 \mathrm{~km})$ to decrease the time needed for data transfer between transient recorder and the laptop (smaller size of data files). At the same time, this provided sufficient number of bins for the required range determined by the altitude of the flying aircraft for nadirpointing configuration, i.e. maximum of $3 \mathrm{~km}$ a.s.l. For this short distance (significantly shorter than the zenith-pointing ground based range), a strong signal with SNR above 15 is guaranteed, so that the PMTs can be operated in an analog mode only (Goodman, 1985). The measurements in nadir-pointing airborne configuration generally provide better SNR at greater distances from the aircraft, as the measured aerosol concentration and the air density increase towards the ground. On the other hand, for the airborne applications only short integration times are permissible in order to achieve a sufficient horizontal resolution. For the available measurement range of $3 \mathrm{~km}$ on board the Polar 2, SNR above 15 is achieved for an integration time of $1 \mathrm{~s}$. This corresponds to a horizontal resolution between $46 \mathrm{~m}$ and $77 \mathrm{~m}$ at a minimum of $166 \mathrm{~km} \mathrm{~h}^{-1}$ and maximum of $278 \mathrm{~km} \mathrm{~h}^{-1}$ aircraft cruising speed over ground, respectively.

For zenith-pointing airborne applications, the collected signal length was set to 1700 bins, which is close to the limit for data transfer. The detectors are read out simultaneously in analog and photon counting mode to increase the measurement range and to compensate the effect of the neutral density filters which reduce the signal intensity. For the evaluation of cloud systems, an integration time of $15 \mathrm{~s}$ is generally chosen, which results in a SNR above 15 at a distance of $4.5 \mathrm{~km}$ off the aircraft, and a horizontal resolution of about $990 \mathrm{~m}$ for the typical cruising speed of $238 \mathrm{~km} \mathrm{~h}^{-1}$.

During daytime the background stray-light photons are collected by the receiving subsystem together with the backscattered laser pulses. Application of the background light correction to the lidar signals is essential in the polar regions were the background light intensity is unusually high due to the high albedo of ice and snow covering most of the sea and land. The limited range of the nadir-pointing airborne signals results in a difficulty to obtain the background light intensity, which has to be subtracted for any further data evaluation. To overcome this, the data acquisition is started by an adjustable pretrigger prior to the laser Q-switch designed by the LICEL GmbH especially for the AMALi airborne applications in the Arctic. The timing of the pretrigger was initialy chosen as a value of $25 \mu$ s corresponding to 500 range bins $(3.75 \mathrm{~km})$. After 2006 a standard pretrigger delay of $20 \mu$ s and $5 \mu$ s was used for nadir- and zenith-pointing measurements, respectively. For the zenith evaluation, the background values can in principle be obtained from the signal values at a far range, (if the conditions allow a reliable estimation of the background signal). However, most of the time the pretrigger is used.

\subsection{Quick-look data processing and display}

The acquired in flight data can be viewed online using an especially designed quick-look data evaluation display in the data acquisition programs (Fig. 3). Each second, a screen displays currently measured raw signal profiles. Other screens are frequently updated with time series of background and range corrected signals at $1064 \mathrm{~nm}$ (or $355 \mathrm{~nm}$ ) and parallel $532 \mathrm{~nm}$ channels (analog and photon counting modes), all averaged over $1 \mathrm{~s}$ or $15 \mathrm{~s}$. The displays can also represent ratios of the signals, e.g. the depolarization ratio $(532 \mathrm{~nm}$ 
perpendicular to $532 \mathrm{~nm}$ parallel signal) or the color ratio ( $532 \mathrm{~nm}$ to $355 \mathrm{~nm}$ signal or $1064 \mathrm{~nm}$ to $532 \mathrm{~nm}$ signal).

The real time quick-look data evaluation software allows immediate qualitative interpretation of the aerosol content and clouds during the flight. This initial information is sufficient for an on board lidar operator to guide another research aircraft for specific measurements. During ASTAR 2004, these quick-looks acted to guide alternated remote and in situ measurements. After identification of particularly interesting regions in mixed-phase clouds (indication of height and relative concentration of water droplet and/or ice crystal areas) by lidar, the aircraft descended into the specified sections of these clouds to perform the in situ measurements of microphyscial and optical parameters (Stachlewska et al., 2006c; Gayet et al., 2007). Similarly, during the ASTAR 2007 the AMALi detected a thin, subvisible ice cloud (Fig. 3). The aircraft returned to the location at the altitude indicated by lidar observations, and the in situ sensors probed single ice crystals (Lampert et al., 2009).

\section{The AMALi lidar data evaluation}

The AMALi lidar provides users with a high quality information on the existence, altitude distribution, vertical and horizontal extent, backscatter and depolarization of tropospheric aerosols and clouds of a low optical thickness. It delivers profiles of the range and background corrected signals, the aerosol backscatter coefficient, and the aerosol particles' non-sphericity (depolarization information). Finally, by the remedy of additional information or instrumentation, even the extinction coefficients can be retrieved.

The elastic lidar equation, usually used in a form of the range corrected signal (Eq. 1), describes the received signal as a function of the atmospheric and system parameters, whereby assumptions of quasi-monochromatic coherent emitted laser light and instantaneous elastic or inelastic scattering are taken into account, while processes of multiple scattering of light are being neglected (Shimoda, 1986)

$$
S(h, \lambda)=P(h, \lambda) h^{2}=C \xi(h) \beta(h, \lambda) T^{2}(h, \lambda)
$$

where $\lambda$ denotes the emitted wavelength and $h$ the distance between the lidar and the target particle or molecule. The detected signal $P(h, \lambda)$ is proportional to the intensity of the detected wavelength dependent backscattered signal at a time $t=2 h / c$. The geometrical efficiency of the detection system $\xi(h)$ is dependent on the geometrical compression (overlap function) and vanishes if the solution of the lidar equation is found at the range $h_{g c}$ where the emitted laser beam is entirely seen by the full field of view of the telescope. $T(h, \lambda)$ is the transmission of the laser energy through the atmosphere (Eq. 2) and $\beta(h, \lambda)$ and $\alpha(h, \lambda)$ are the total backscatter and the total extinction coefficients. When the absorption of the emitted wavelength in the atmosphere is negligible they split to the molecular terms $\beta^{\mathrm{mol}}(h, \lambda)$ and $\alpha^{\mathrm{mol}}(h, \lambda)$ due to the

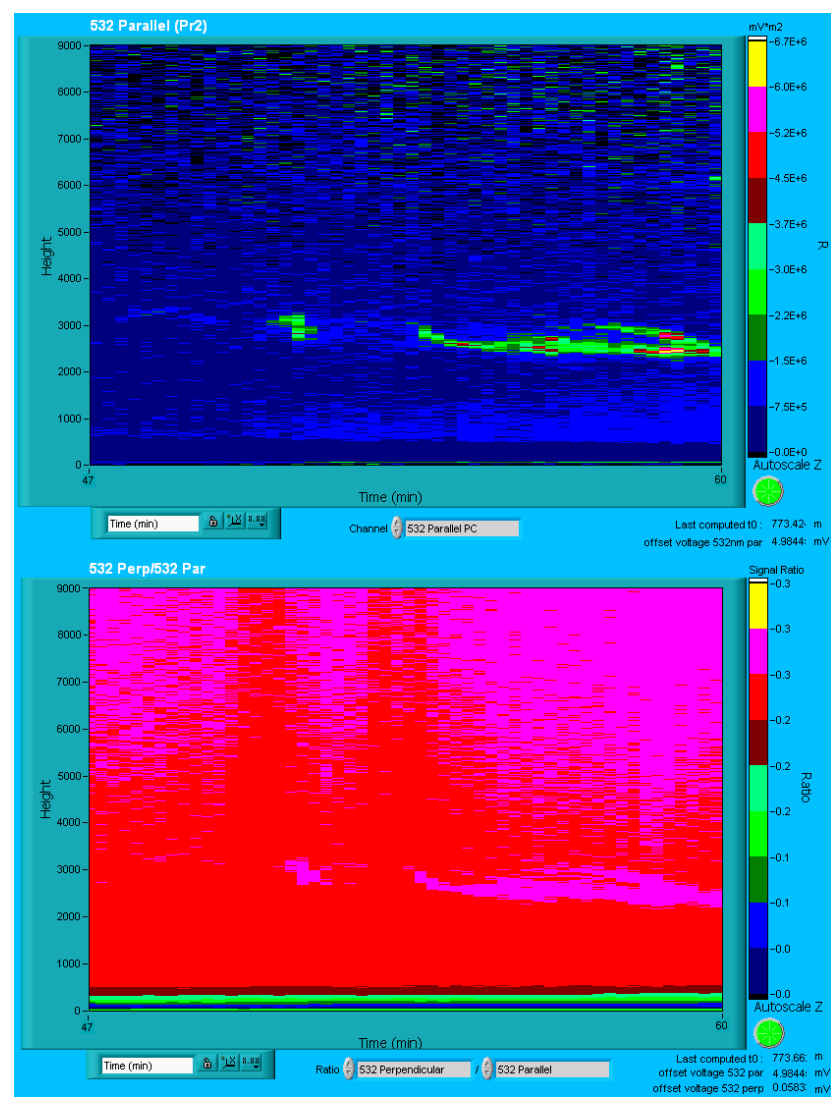

Fig. 3. The real-time quick-look display in the AMALi online software during a zenith-pointing configuration on board the Polar 2 aircraft provided the range and background corrected signals at $532 \mathrm{~nm}$ with the corresponding depolarization ratios during the flight. On this day it allowed the observation of a subvisible ice cloud at $3 \mathrm{~km}$ above the flight altitude of $160 \mathrm{~m}$ a.g.

Rayleigh scattering on the gaseous constituents of the atmosphere and the particle terms $\beta^{\text {part }}(h, \lambda)$ and $\alpha^{\text {part }}(h, \lambda)$ due to the Lorenz-Mie scattering on aerosols in the atmosphere.

$T(h, \lambda)=\exp \left(-\int_{h_{0}}^{h} \alpha(\tilde{h}, \lambda) d \tilde{h}\right)$

The terms describing the range independent parameters of the lidar system appear in the definition of the lidar instrumental constant $C=P\left(h_{0}, \lambda\right) \epsilon(\lambda) \Delta h A$. The mean number of photons in the emitted laser pulse $P\left(h_{0}, \lambda\right)$ corresponds to the intensity of the wavelength dependent laser pulse emitted at a time $t_{0}$. The spectral efficiency of the detection system $\epsilon(\lambda)$ depends on the spectral efficiencies of the photo-detectors and the spectral transmittance of the optical elements. The $A$ denotes the effective telescope surface and $A / h^{2}$ is the solid angle of signal collection. Finally, the $\Delta h$ describes the spatial resolution of the system, which is determined by the laser pulse duration $\tau$ by definition. In reality it is limited by the slowest component of the system (detector efficiency or transient recorder speed) and hence always $\Delta h \gg c \tau / 2$. 
The ground based pulse-to-pulse fluctuations of the lidar constant $C$ have been investigated each time before using the AMALi in the Arctic. The utilized laser has a very low pulseto-pulse power variability (for $80 \%$ energy (NF 8 ) at $15 \mathrm{~Hz}$ laser power fluctuations between $10^{-2}$ to $10^{-3}$ were measured). The optical assembly is closed entirely to achieve after $30 \mathrm{~min}$ the thermal stabilization at 35 Celsius (interior warm up due to switching on the laser), which is continuously measured using a temperature sensor (MINIDAN Temp 0,1, ESYS GmbH, Berlin). The measurements are either started after the warm up time or higher errors are expected for the first $30 \mathrm{~min}$. Prior to the Arctic campaigns we tested the variability of the lidar constant $C$ by taking ground based quasi-horizontal measurements in clear air conditions after rain episodes during the night. The measurements were acquired at an inclination angle of 2.5 degree pointing out from the laboratory window over a total $6 \mathrm{~h}$ period for two PMT settings ( $750 \mathrm{~V}$ and $850 \mathrm{~V}$ ). The range and background corrected single-shot signals were plotted in a logarithmic scale, and from the slope of the linear fit to these profiles, the values of $C$ were obtained. The spread of the $C$ value was between 3\% and 5\% for each PMT setting, whereby the larger spread was obtained for the lower PMT setting. Similarly, it was done for a period of about $30 \mathrm{~min}$ on one day of the single-shot horizontal ground-based measurements performed in the Arctic and there the $C$ values spread was about $2 \%$ for 850 V PMT setting. We calculated the $C$ also using a method described in Stachlewska and Ritter (2010) and in this case the spread was from $2.3 \%$ to $6.9 \%$ at different PMT settings. Again the largest spread was obtained for the lowest applied PMT voltage.

The long term power fluctuations of the flashlamp are an issue for regular long term lidar measurements. The AMALi is not used for monitoring of the atmosphere but for applications during dedicated campaigns of a duration of a month or two at most. Before each campaign the flashlamps are exchanged and their power fluctuations are considered not to be an issue. The fact that similar lidar constants were measured in different years with different PMT's settings show that no major change of laser power occurred. The sensitivity variation on the detector's surfaces was also of no concern. After performing the tests described above no adjustments of the optical elements were applied during a particular campaign. During the test flights a final set of measurement parameters was selected and left unchanged for consistency. As the optics were not realigned during an entire campaign the position of the light focus on the detector's surface also remained unchanged. After the optical assembly reached the thermal stabilization, there is no effect of the temperature on the optics and the alignment, so changes of the lidar constant $C$ from flight to flight due to alignment were not an issue.

The range corrected signal (Eq. 1) provides the lidar user with a qualitative information on the existence and altitude distribution of aerosols and clouds of a low optical thickness. The quantitative information can be obtained via in- version of the lidar signals and calculation of the profiles of the particle backscatter $\beta^{\text {part }}(h, \lambda)$ and the particle extinction $\alpha^{\text {part }}(h, \lambda)$. The main difficulty of such an inversion is caused by the existence of two unknowns $(\alpha$ and $\beta$ ) in one lidar equation (Eq. 1), so that no unique solution can be found. The overview of the solutions applied to invert the AMALi signals is given in Table 2 .

For the horizontally-pointing ground based AMALi configuration we use the slope method (Klett, 1981; Kunz and de Leeuw, 1993) when the assumption of an aerosol rich homogeneous atmosphere can be made (e.g. in the planetary boundary layer). Then the molecular terms $\beta^{\mathrm{mol}}(h, \lambda)$ and $\alpha^{\mathrm{mol}}(h, \lambda)$ can be neglected, the changes of the backscatter coefficient in the interval $d h$ are negligible $\left(\frac{d}{d h} \beta^{\text {part }}(h)=0\right)$ and the aerosol extinction coefficient can be directly calculated from $\alpha^{\text {part }}(h)=-\frac{1}{2} \frac{d}{d h} S(h)$. Extinction profiles obtained with the slope method from signals averaged over $1 \mathrm{~min}$ with $7.5 \mathrm{~m}$ range resolution (SNR above 15 ) range from the overlap to $4 \mathrm{~km}$, horizontaly.

For the slant measurements we use the two-angle or multiangle approach (Sicard et al., 2002; Kovalev and Eichinger, 2004; Pahlow et al., 2004) when the atmosphere is stable and characterised by a strong stratification.

For the vertically-pointing configuration the assumption of the homogeneity of the atmosphere cannot be made. In this case we use the Klett-Fernald-Sasano's backward approach (Klett, 1981, 1985; Fernald, 1984; Sasano et al., 1985). To invert the lidar signals an altitude dependent lidar ratio $B(h, \lambda)=\frac{\alpha^{\mathrm{part}}(h, \lambda)}{\beta^{\operatorname{part}}(h, \lambda)}$ is assumed and the equation is solved with respect to the particle backscatter coefficient. The height independent lidar constant $C$ proves redundant in these calculations. The direct measurements of the lidar ratio and its calculations from Mie theory show that the relationship between extinction and backscatter is highly variable, as it strongly depends on the highly variable size distribution of the scattering particles in the atmosphere. A wrong estimation of the lidar ratio is a dominant factor, that causes ambiguity in the solution of the classic elastic lidar equation (Kovalev and Eichinger, 2004). The estimation of the rangedependent lidar ratio is challenging unless independent information on the extinction is obtained by inelastic techniques, e.g. with the Raman method (Ansmann et al., 1990) or the High-Spectral-Resolution method (Shipley et al., 1983). The assumption of the lidar ratio for the iterative airborne approach is discussed on an example of a real data in Sect. 5.

The Klett-Fernald-Sasano's backward inversion is performed starting with a point chosen far from the lidar where the signals are normalized to the molecular elastic backscatter profile at an altitude range where the signal is only caused by the molecular contribution. To obtain the $\alpha^{\text {part }}(h, \lambda)$ and $\beta^{\text {part }}(h, \lambda)$ the profiles of the the $\alpha^{\mathrm{mol}}(h, \lambda)$ and $\beta^{\mathrm{mol}}(h, \lambda)$ in the Rayleigh atmosphere are subtracted. They are calculated using the radiosonde data launched in direct vicinity within $\pm 2 \mathrm{~h}$ from the AMALi measurements. If radiosonde 
Table 2. The AMALi retrievals obtained with different measurement configurations and evaluation schemes. The symbols denote $\alpha$ extinction coefficient, $\beta$ backscatter coefficient, $B$ lidar ratio, $C$ lidar instrumental constant, $T$ atmospheric transmittance, SNR signal-to-noise ratio, KFS Klett-Fernald-Sassano.

\begin{tabular}{|c|c|c|c|}
\hline Ground based configuration & horizontal & slant & $\begin{array}{l}\text { vertical } \\
\text { (or airborne zenith-pointing) }\end{array}$ \\
\hline Evaluation method & slope & multiangle & standard backward KFS \\
\hline Assumptions & homogeneous atmosphere & stable stratification & $\begin{array}{l}\beta_{\text {ref in aerosol free layer far }} \\
\text { from lidar, } B(h)\end{array}$ \\
\hline Retrieval & $\alpha, \beta, \mathrm{C}$ & $\alpha(h), \beta(h)$ & {$[\alpha(h)], \beta(h)$} \\
\hline Required SNR & 10 & 15 & 10 \\
\hline Integration time & $1 \mathrm{mn}$ & $1 \mathrm{mn}$ & $1 \mathrm{mn}$ \\
\hline Measurement range & $4 \mathrm{~km}$ & $10 \mathrm{~km}$ & tropopause \\
\hline \multirow[t]{3}{*}{ References } & Klett, 1981 & Sicard et al., 2002 & Klett, 1981, 1985 \\
\hline & Kunz and Leeuw, 1993 & Pahlow et al., 2004 & Fernald, 1984 \\
\hline & & & Sassano, 1985 \\
\hline Airborne configuration & nadir-pointing & $\begin{array}{l}\text { nadir-pointing combined } \\
\text { with ground based } \\
\text { zenith-pointing KARL }\end{array}$ & $\begin{array}{l}\text { zenith-pointing combined } \\
\text { with spaceborne } \\
\text { nadir-pointing CALIPSO }\end{array}$ \\
\hline Evaluation method & $\begin{array}{l}\text { backward KFS with } \\
\text { Newton-Raphson iterative }\end{array}$ & two-stream & two-stream \\
\hline Assumptions & $\begin{array}{l}T=1 \text { within overlap range, } \\
\text { stable known } C, B(h)\end{array}$ & $\begin{array}{l}\beta_{\text {ref at arbitrary height }} \\
\text { or knowledge of } C\end{array}$ & $\begin{array}{l}\beta_{\text {ref at arbitrary height }} \\
\text { or knowledge of } C\end{array}$ \\
\hline Retrieval & {$[\alpha(h)], \beta(h)$} & $\alpha(h), \beta(h), C_{\mathrm{AMALi}}, C_{\mathrm{KARL}}$ & $\alpha(h), \beta(h), C_{\mathrm{AMALi}}, C_{\mathrm{CALIPSO}}$ \\
\hline Required SNR & 10 & 15 & not determined \\
\hline Integration time & $1 \mathrm{mn}$ & $8 \mathrm{mn}$ & not determined \\
\hline Measurement range & $3 \mathrm{~km}$ & $650 \mathrm{~m}-3 \mathrm{~km}$ & not determined \\
\hline \multirow[t]{5}{*}{ References } & Stachlewska et al., 2006 & Kunz, 1987 & Cuesta and Flamant, 2004 \\
\hline & Gayet et al. 2007 & Hugges and Paulson, 1988 & Wang et al., 2007 \\
\hline & Dörnbrack et al. 2010 & Stachlewska et al., 2005 & \\
\hline & & Ritter et al., 2006 & \\
\hline & & Stachlewska and Ritter, 2010 & \\
\hline
\end{tabular}

measurements were not available we took molecular profiles of the average atmosphere typical for particular month in $\mathrm{Ny}$ Ålesund (obtained from the local radiosonding climatology data) or we calculated them from the the standard US atmosphere profiles. When cirrus clouds appear in the troposphere the calculations are calibrated in the cirrus region (Ansmann et al., 1992) and treated with an uniform lidar ratio obtained by the transmittance method (Chen et al., 2002) applied separately to each cirrus case.

Finally, the unitless backscatter ratio profiles are calculated (Eq. 3) where the BSR of 1 corresponds to pure Rayleigh scattering by the molecules of the air. In the Arctic typical values of BSR range from 1.01-1.6 for the clear free troposphere. For atmosphere polluted with the Arctic haze (Yamanouchi et al., 2005) the BSR reach values up to 5 in the free troposphere and up to 10 near the ground. For the sea-salt aerosol in the Arctic marine boundary layer the BSR values range from 2 to 4 . For Arctic subvisible clouds the BSR values reach up to 10 , and for optically thick water clouds they exceed 30 .
$\operatorname{BSR}(h, \lambda)=\frac{\beta^{\mathrm{mol}}(h, \lambda)+\beta^{\mathrm{part}}(h, \lambda)}{\beta^{\mathrm{mol}}(h, \lambda)}$

The zenith-pointing ground based profiles typically obtained with the Klett-Fernald-Sasano's backward approach are evaluated for cloudless conditions. With $1 \mathrm{~min}$ temporal and $7.5 \mathrm{~m}$ range resolution these reach the tropopause level. For the airborne zenith-pointing profiles the averaging depends on the aim of the measurements and the distance of the structures of interest. For example for the comparison of lidar profiles with space borne CALIOP, a temporal average of $15 \mathrm{~s} \mathrm{re-}$ sults in a similar horizontal resolution as the average of three single CALIOP profiles of about $1 \mathrm{~km}$. Cirrus clouds up to $6 \mathrm{~km}$ can be evaluated using this resolution. A 1 min temporal and $7.5 \mathrm{~m}$ range resolution results in calculation range up to the Arctic tropopause level.

Measurements of the depolarization ratio provide information to discriminate between spherical and non-spherical particles in the atmosphere and are helpful in distinguishing between liquid and solid phase particles. If a lidar system simultaneously detects the backscattered light polarized in 
parallel and perpendicular direction with respect to the emitted laser beam, the total volume depolarization ratio DR, i.e. the depolarization induced by atmospheric particles and molecules can be obtained (Eq. 4).

$\mathrm{DR}(h, \lambda)=\mathrm{DR}^{\mathrm{mol}}(h, \lambda)+\mathrm{DR}^{\mathrm{part}}(h, \lambda)=\frac{P_{\mathrm{perp}}(h, \lambda)}{P_{\mathrm{par}}(h, \lambda)}$

As the detection of both the $P_{\text {perp }}(h)$ and $P_{\text {par }}(h)$ signals is done using two different opto-electronic detection channels characterized with a different gain, both signals must be well calibrated to provide high quality measurements. This can be done by instantaneous calibration using the normalization of the real signal to the molecular elastic backscatter one in an altitude range where the signal is only caused by the molecular contribution with a known and constant depolarization of 0.00376 (Behrendt and Nakamura, 2002). Usually the height interval in the free troposphere which appears to be clearest is used for this normalization. However, the molecular depolarization ratio depends on the amount of rotational Raman scattering detected. The stated value is the minimum ratio. Even a small amount of background aerosol in the free troposphere can change the depolarization ratio significantly. Various calibration methods are known (Biele et al., 2000; Reichardt et al., 2003; Alvarez et al., 2006; Gimmestad, 2008; Freudenthaler et al., 2009). For AMALi the relative efficiency factor of both channels (cross-parallel/co-parallel) is determined. The linear particle depolarization ratio (Biele et al., 2000) is retrieved by division of the perpendicular particle backscatter coefficient profile by the parallel particle backscatter coefficient profile. Both backscatter profiles are obtained with the Klett-Fernald-Sassano method with calibration in tropopause or with the iterative airborne inversion described in this paper which is calibrated with known backscatter coefficient value near the aircraft. Otherwise we use the calibration in clear air of $1.4 \%$ or less (depending on the spectral bandpass of the filter). Normally the cross-talk between the two channels needs to be accounted for but in the AMALi the crosstalk measured experimentally is negligible $\left(10^{-6} \%\right.$ parallel to perpendicular).

\section{AMALi and KARL intercomparison}

For two measurements taken with two different lidars, at the same wavelength, time and aim, and with application of the same profile averaging in time and space, their signal statistics can still differ significantly due to differences in the emitted laser power and field of view of their receiving telescopes (Matthias et al., 2004). The system intercomparison is crucial to assess their ability to obtain the same results when the same evaluation scheme is applied.

The Koldewey Aerosol Raman Lidar (KARL; Ritter et al., 2004) is a ground based system integrated at the Koldewey Station in Ny-Ålesund, Spitsbergen (78.9 N, 11.9 E). It is used for the detection of tropospheric aerosols and water vapor. During ASTAR 2004 the KARL system employed the Nd:YAG laser operating with $30 \mathrm{~Hz}$ repetition rate at the three basic harmonics, each with energy around $2 \mathrm{~W}$. The receiving system based on two mirrors uses the smaller one $(10.8 \mathrm{~cm}$ diameter with FOV of $2.25 \mathrm{mrad})$ for near range measurements from $650 \mathrm{~m}$ to $6 \mathrm{~km}$. The larger mirror ( $30 \mathrm{~cm}$ diameter with FOV of $0.83 \mathrm{mrad}$ ) is used for far range measurements from $2 \mathrm{~km}$ to the lower stratosphere. The KARL detects the elastic backscatter at $355 \mathrm{~nm}, 532 \mathrm{~nm}$ and $1064 \mathrm{~nm}$, the depolarization at $532 \mathrm{~nm}$, and Raman-shifted wavelengths for nitrogen at $387 \mathrm{~nm}$ and $607 \mathrm{~nm}$ and for water vapor at $407 \mathrm{~nm}$ and $660 \mathrm{~nm}$. In November 2006 KARL was modified and during ASTAR 2007 measured with the new Nd:YAG laser (Spectra Pro 290-50) working at $50 \mathrm{~Hz}$ with $10 \mathrm{~W}$ at $355 \mathrm{~nm}$ and $532 \mathrm{~nm}$ and $20 \mathrm{~W}$ at $1064 \mathrm{~nm}$. An increase of the energy output by a factor of 5 significantly improved the KARL's data quality (Richter et al., 2008). After beam widening the laser has an effective divergence of $0.5 \mathrm{mrad}$. With the typically used $10 \mathrm{~min}$ integration time and $60 \mathrm{~m}$ height resolution the elastic wavelengths can be analyzed up to $25 \mathrm{~km}$ altitude under daylight conditions.

The intercomparison measurements of the AMALi and the KARL lidars were performed with both systems operating simultaneously at $532 \mathrm{~nm}$ in zenith-pointing ground based configuration under the clear-sky weather conditions typically chosen for lidar measurements. Observations were performed between 21:30-22:10 UT on 15 June 2004 at the Koldewey Station. The lidars were placed approximately $30 \mathrm{~m}$ apart to ensure that each laser beam and telescope field of view did not overlap. The KARL recorded data up to the tropopause and the AMALi up to $7.5 \mathrm{~km}$. Both signals were initially compared by simple division of background and range corrected signals averaged to the same spatial $(60 \mathrm{~m})$ and temporal $(5 \mathrm{~min})$ intervals. Afterwards, the backscatter ratio profiles were retrieved for both lidars using the KlettFernald-Sasano approach with the assumption of a height independent lidar ratio of $30 \mathrm{sr}$. For this retrieval a calibration value has to be set at the far range from the lidar and in clear atmosphere where the lidar does not detect aerosol particles (Klett, 1981; stable backward solution). As the KARL system provides the opportunity to calibrate the signals even in the stratosphere we used its signals for the initial calibration (with a backscatter ratio value of 1.05) to assure the best accuracy of the KARL retrievals. At the altitude $4.8-5 \mathrm{~km}$ where the AMALi profiles had a SNR above 15 we obtained a realistic value of the KARL backscatter ratio of 1.26 and used this value to calibrate the AMALi retrievals. It is worth noting that although the Arctic is generally considered clear and sparse in aerosol the backscatter ratio 1.05 on that day would be too low for the free troposphere at $5 \mathrm{~km}$.

The temporal evolution of the backscatter ratio profiles for both lidars obtained over the whole observation period on that day is given in Fig. 4. On the same figure the profiles integrated over $20 \mathrm{~min}$ intervals (red and green) at 21:30 UT and 21:50 UT as well as the profiles integrated over the entire 
measurement period (blue and black) are presented. The agreement of KARL and AMALi retrievals is very good with deviations less than 3\%. Stronger deviations, up to $30 \%$ at the range below $750 \mathrm{~m}$ occur due to the incorrect adjustment of the KARL's near-range small mirror on that particular day, i.e. the KARL's backscatter profiles are strongly underestimated in this range. The variability in the backscatter ratio values at a layer between $1.4 \mathrm{~km}$ and $2.4 \mathrm{~km}$ altitude are caused by passing thin, subvisible clouds, well captured by both lidars. As seen over a 20 min integration both lidar retrievals converge, i.e. deviations in this height interval are mainly due to the high temporal and spatial variability of these clouds. The condensation in this layer must be dominated by small scale processes with a life time shorter than 20 min since the averaging of the lidar signals is just sufficient to smear them out.

Good agreement of the profiles above the mentioned KARL's lower range give evidence that both lidars obtain the same results. Neither lidar display specific problems with the raw signal. Noise in the signals and/or the detection efficiencies of both instruments are of no concern due to the high SNR. The error in the backscatter ratio due to the noise in the data is negligible (less than 0.01 for KARL at $4.8 \mathrm{~km}$ ) and becomes weaker when the SNR becomes stronger, i.e. the closer it is measured from the lidar. This is also true for the AMALi. All remaining errors due to the choice of the lidar ratio, the choice of the reference value in the aerosol free stratosphere and the error in the air density profile are greater than the error due to noise in the signal. The error due to the lidar ratio assumption is a main error source, but it affects both systems in the same way as we used identical and constant lidar ratio value of $30 \mathrm{sr}$ (studied in detail by Sasano et al., 1985).

Further examples of AMALi and KARL intercomparisons of the backscatter extinction are discussed in Stachlewska et al. (2005); Stachlewska (2006b); Ritter et al. (2006); Stachlewska and Ritter (2010). The AMALi results were also compared with the in situ instrumentation installed on board of the aircraft for the studies involving various cloud systems and are discussed in Stachlewska et al. (2006c); Gayet et al. (2007); Lampert et al. (2009).

\section{Nadir-pointing iterative airborne inversion}

The standard Klett-Fernald-Sasano's backward approach cannot be used straight forward for the data evaluation of any nadir-pointing airborne elastic lidar measuring alone in the lower troposphere. The main problem of using this standard scheme arises from the difficulty of providing the calibration value for each of the profiles. The lowermost part of the troposphere is usually rich in turbulent aerosol particles generated by surface winds. In these areas the backscatter coefficient is highly variable during the flight and hence it is very difficult to estimate, since the phase function de-

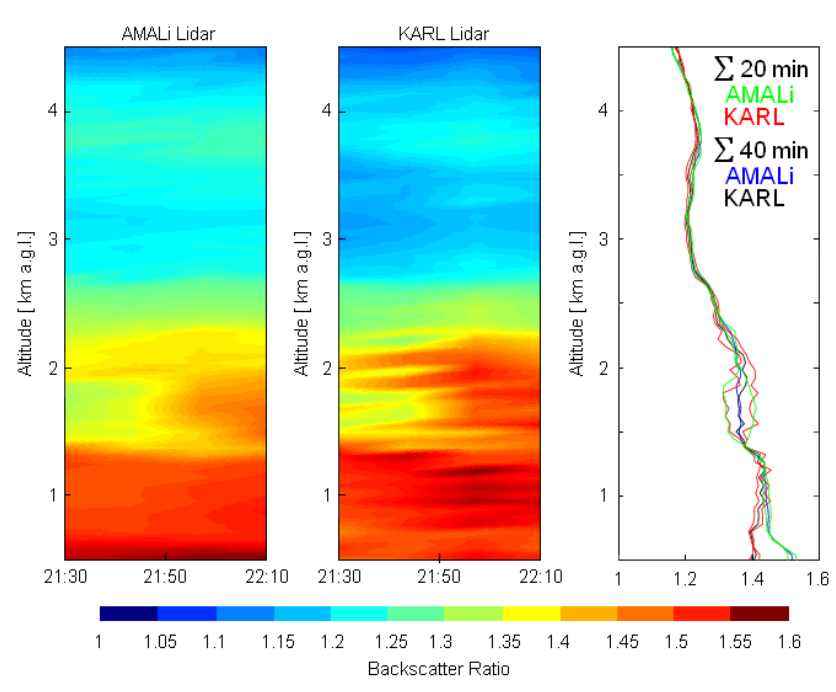

Fig. 4. The comparison of the $532 \mathrm{~nm}$ backscatter ratio profiles retrieved from measurements taken between 21:30-22:10 UT on 15 June 2004 for AMALi and KARL. Both lidars operated in zenith-pointing ground based configuration and captured subvisible clouds passing above the lidar site at about $1.5-1.8 \mathrm{~km}$. The original data of the color coded pictures have $10 \mathrm{~min} / 60 \mathrm{~m}$ resolution and are interpolated by the contour routine in Matlab.

pendence with height has to be accounted for. It is similarly difficult to provide any reference backscatter values in the lower troposphere due to the lack of aerosol free layers. Also the limited signal range between the flight altitude and ground/sea level adds to the signal calibration problem.

Here we present an iterative approach for the calculation of the backscatter coefficient profiles from the airborne elastic backscatter lidar data, independent of the existence of aerosol free layers or in situ calibration measurements. The application of this new approach facilitates the retrieval of profiles of calibrated backscatter ratios $\operatorname{BSR}(h)$ at any time during the whole flight. A typical backscatter coefficient profile obtained with this method is averaged over $15 \mathrm{~s}$ with $7.5 \mathrm{~m}$ range resolution and $1 \mathrm{~km}$ horizontal resolution for $66 \mathrm{~ms}^{-1}$ aircraft's cruising speed over ground. Examples of the application of this method can be found in Stachlewska and Dörnbrack (2006a); Stachlewska et al. (2006c); Gayet et al. (2007); Dörnbrack et al. (2010).

To apply the iterative approach one must assume state that for a short (few hundred meters) range $h_{g c}$ over which the geometrical compression is completed $\left(\xi\left(h \geq h_{g c}\right)=1\right)$, the assumption of a negligible attenuation of the emitted laser light between the flight altitude $h_{f}$ and geometrical compression $h_{g c}$ is justified (Eq. 5).

$T_{\left[h_{f}, h_{\mathrm{gc}}\right](h, \lambda)} \approx 1-\left(h_{f}-h_{g c}\right) \cdot \alpha\left(h_{f}\right)<1$

By neglecting the transmittance term the backscatter at the altitude $h_{g c}$ can be estimated for each time step during the 
Table 3. The constraints on the lidar ratio dependent on the air type and the corresponding errors of the backscatter coefficient calculation using the iterative method.

\begin{tabular}{lcc}
\hline Arctic air type & $\mathrm{B}(\mathrm{h})=$ const $[\mathrm{sr}]$ & $\Delta \beta^{\text {part }}\left[\mathrm{m}^{-1} \mathrm{sr}^{-1}\right]$ \\
\hline clean & 20 & $\pm 1.8 \times 10^{-7}$ \\
low aerosol load & 25 & $\pm 0.3 \times 10^{-7}$ \\
considerable aerosol load & 30 & $\pm 0.7 \times 10^{-7}$ \\
polluted & 35 & $\pm 1.4 \times 10^{-7}$ \\
highly polluted & 60 & $\pm 2.6 \times 10^{-7}$ \\
\hline
\end{tabular}

flight (Eq. 6) for known lidar constant $C$.

$\beta\left(h_{g c}\right)>\frac{S\left(h_{g c}\right)}{C}$

The knowledge of $\beta\left(h_{g c}\right)$ for each consecutive profile allows for an application of the standard Klett-Fernald-Sasano's backward procedure with the following constraints. The backscatter coefficient calibration value $\beta_{\mathrm{KFS}}\left(h_{\text {ref }}\right)$ is chosen in a far distance from the lidar and it is set in a way that the value of the backscatter coefficient $\beta_{\mathrm{KFS}}\left(h_{g c}\right)$ calculated using the Klett-Fernald-Sasano's backward inversion at the height corresponding to the completed geometrical compression, matches the estimated value of $\beta\left(h_{g c}\right)$. If these do not match, the $\beta_{\mathrm{KFS}}\left(h_{\mathrm{ref}}\right)$ is recalculated accordingly to the classical numerical Newton-Raphson iterative approach for finding zeros of real valued functions, until the two values are the same. Of course the extinction in the overlap region can be also estimated to calculate the transmission term of the lidar equation. The clearer the atmosphere and the better $\alpha^{\mathrm{mol}}$ is known, the better the transmittance of the layer $\left[h_{f}, h_{g c}\right]$ can be estimated and the error of $\beta\left(h_{g c}\right)$ decreases. Hence, the iterative approach provides calibrated $\beta$ profiles and $\alpha$ profiles calculated with the uncertainty of the assumed lidar ratio $B(h)$.

This method can be applied to any ground based or airborne lidar independently of the pointing direction in which the lidar beam is sent. It is useful, especially in the cases when the calibration value cannot be estimated (lack of an aerosol-free layer) or cannot be provided a priori (from an additional on board in situ calibration instrumentation, and/or on board horizontal or vertical scanning of the emitted lidar light is not available). Only two assumptions are made: the standard Klett solution is applicable and the lidar constant $C$ is known by calibration (e.g. Stachlewska and Ritter, 2010) or other means.

In the case of the AMALi operated in nadir-pointing mode from an aircraft in the Arctic we apply the iterative method as follows:

1. We assume the transmission term is equal unity, as in the Arctic the losses of the AMALi laser signal due to extinction in its overlap range can be neglected (for an extinction coefficient of $2 \times 10^{-5}$ per meter and $235 \mathrm{~m}$ overlap range the $\exp \left(-2 \times 2 \times 10^{-5} \times 235\right)=$ 0.99 , i.e. only $1 \%$ loss is due to extinction).

2. The backscatter coefficient at the end of the overlap is directly determined from Eq. (6) with known lidar constant $C$.

3. The backward Klett-Fernald-Sassano approach is performed with an arbitrary boundary condition $\beta_{\mathrm{KFS}}\left(h_{\mathrm{ref}}\right)$.

4. With knowledge of the partial derivative $\frac{\partial \beta\left(h_{\mathrm{gc}}\right)}{\partial \beta_{\mathrm{KFS}}\left(h_{\mathrm{ref}}\right)}$ the boundary condition $\beta_{\mathrm{KFS}}\left(h_{\text {ref }}\right)$ is changed in a NewtonRaphson scheme until the value of backscatter in the $\beta_{\mathrm{KFS}}\left(h_{\mathrm{gc}}\right)$ matches to the value at the end of the overlap $\beta\left(h_{\mathrm{gc}}\right)$. Generally, less than 5 iterative steps are required.

An example of an application of the iterative airborne inversion to obtain the calibrated backscatter ratio profiles along the flight path for measurement on 19 May 2004 during the ASTAR 2004 campaign depicts Fig. 5. The backscatter ratio profiles were calculated with $15 \mathrm{~s}$ temporal resolution corresponding to $1 \mathrm{~km}$ spatial resolution. In case of thick clouds the backscatter ratio could not be retrieved due to the multiple scattering. For these calculations the AMALi instrumental constant $C_{A}$ was found experimentally for several atmospheric conditions according to the methodology described in (Stachlewska and Ritter, 2010) from the simultaneous measurements of AMALi and KARL taken during the Koldewey Station overflights. The $C_{A}=1.43( \pm 0.1) \times 10^{13} \mathrm{~m} \mathrm{~V} \mathrm{~m}^{3}$ sr was obtained for the overflight at about 09:35 UTC on 19 May 2004. The lidar ratio profile obtained at the same time from the KARL data predominantly showed background values of the lidar ratio of $20 \mathrm{sr}$ with a layer of extremely high values of the lidar ratio of $80 \mathrm{sr}$ at about $1.8 \mathrm{~km}$ in an aerosol layer of local origin. The air mass transport calculated with the Hybrid Single-Particle Lagrangian Integrated Trajectory (HYSPLIT) model displayed a non-uniform character, whereby contamination by anthropogenic aerosol could not be totally excluded. Hence, the choice of the appropriate lidar ratio for calculations along the entire flight was not straight forward. We did not use the KARL's lidar ratio profile as it was representative only for a local vertical measurement at $\mathrm{Ny}$ Ålesund. Multiple inversion layers often observed here and related to the complicated orography of the fjord (Dörnbrack et al., 2010; Stachlewska and Ritter, 2010) cannot be used for the atmospheric conditions outside the fjord where we took most of the measurements during the ASTAR campaigns.

Therefore, a sensitivity study to estimate the error due to assumption of a different lidar ratios was performed. For each constraint on the lidar ratio specified in Table 3 the error 

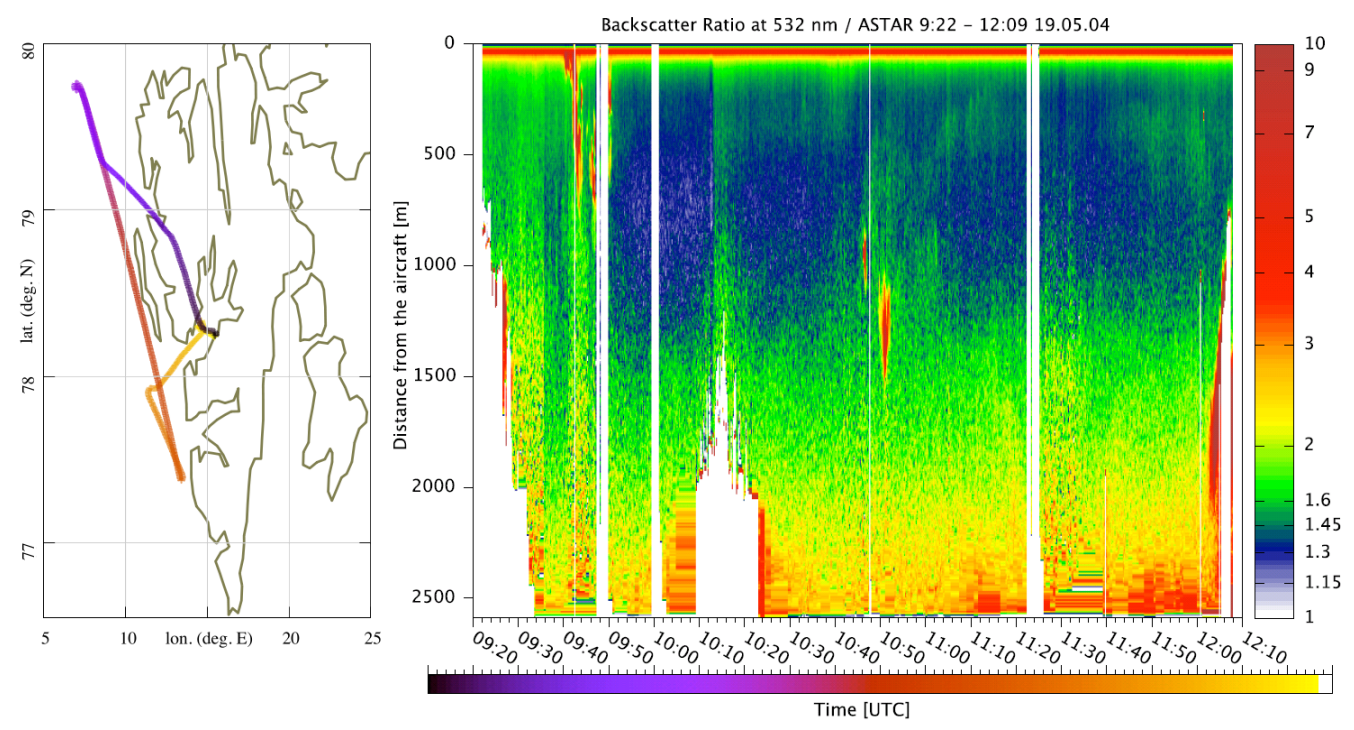

Fig. 5. The calibrated backscatter ratio profiles (right) retrieved using the iterative method along the flight path (left) on 19 May 2004 . The data were obtained by the nadir-pointing airborne AMALi lidar from a flight altitude of $2650 \mathrm{~m}$ during the ASTAR 2004 campaign. The bottom color scale denotes the change of the position of the Polar 2 aircraft with time. At about 10:15 the Polar 2 took the north-turn and at about 11:15 the south-turn. The white areas in the backscatter ratio profiles indicate lack of signal due to overflying mountains (09:21-09:32) or signal saturation in optically thick clouds (remaining).

of the backscatter coefficient calculation was obtained. Additional calculations were performed for the height dependent lidar ratio set to $35 \mathrm{sr}$ between $0-1600 \mathrm{~m}$ and to 20 sr at 1600 $2500 \mathrm{~m}$, for which (within the given uncertainties in Table 3) the same values of the particle backscatter coefficient errors were obtained as for the results calculated with the constant lidar ratios. This sensitivity study shows no significant hindrance to the iterative calculations when a constant lidar ratio is assumed, mainly due to the short integration range of the AMALi measurements (maximum $3 \mathrm{~km}$ ). The accuracy of the backscatter coefficient obtained with the iterative approach is at most $\Delta \beta^{\text {part }}=2.6 \times 10^{-7} \mathrm{~m}^{-1} \mathrm{sr}^{-1}$. For comparison the accuracy of the molecular backscatter coefficient is $\Delta \beta^{\mathrm{mol}}=4.2 \times 10^{-8} \mathrm{~m}^{-1} \mathrm{sr}^{-1}$.

The resultant backscatter ratios (Fig. 5) were interpreted using ECMWF operational analyses in Stachlewska and Dörnbrack, 2006a and studied in detail using the high resolution numerical model EULAG in Dörnbrack et al., 2010. For the mentioned AMALi overflight over the KARL at 09:35 UTC the extinction and backscatter coefficient profiles were derived from both lidars using the two-stream method and the Raman method. Their comparison with two more overflights in clean and polluted Arctic conditions are discussed in Stachlewska and Ritter, 2010.

The uncertainty of the iterative method depends on several error sources. The assumption of the transmittance term $T=1$ in the airborne lidar equation permits the estimation of $\beta\left(h_{g c}\right)$ over range intervals close to the lidar, i.e. at an altitude near the aircraft but beyond geometrical compression of the lidar. In case of the AMALi lidar, for the height cho- sen just below the maximum value of overlap of $235 \mathrm{~m}$ the expected error for neglecting the transmittance term varies from $0.7 \%$ for the particle extinction of $0.15 \times 10^{-4} \mathrm{~m}^{-1}$ typical for clear Arctic atmosphere $(T \approx 0.993)$, up to $2.8 \%$ for the particle extinction of $0.6 \times 10^{-4} \mathrm{~m}^{-1}$ for aerosol contaminated atmosphere $(T \approx 0.972)$. The error of the backscatter coefficient depends linearly on the transmission term, so that any difference between $T=1$ and $\mathrm{T}=0.97$ can be neglected (error 1-3\%) for the iterative method. Due to the iterative approach the boundary condition can be estimated dependent upon the accuracy of the determination of the lidar constant $C$ (error 2-7\%). Hence, only three sources of errors remain. The error due to the choice of the molecular contribution, which is proportional to the air density in our case known from radiosonding (error of about 5\%), hence this error is negligible. The error due to the signal noise in the lidar data, which is also negligible for SNR above 15 (error of about $5 \%$ ). Finally, the error due to the assumption of the lidar ratio, which dominates the error budget of the solution, however, as the partial derivative $\frac{\partial \beta(h)}{\partial B(h)}$ can be calculated this error can be estimated (results are given in Table 3 ).

\section{Combined nadir-pointing and zenith-pointing inversion}

The two-stream method (Kunz, 1987; Hughes and Paulson, 1988, revised recently by Cuesta and Flamant, 2004; Stachlewska et al., 2005; Wang et al., 2007; Stachlewska and Ritter, 2010) can be applied for two lidars pointing at each 
other allowing for the direct calculation of the extinction and backscatter coefficient profiles, and hence the lidar ratio profiles. In our case the elastic signals measured by the zenithpointing ground based KARL are combined with the signals from the nadir-pointing AMALi overflying it. The profiles of the extinction and backscatter coefficients are obtained directly from the colocated in time and space airborne and ground based signals by their division (extinction) and multiplication (backscatter). Typically the two-stream profiles are calculated with $8-10 \mathrm{~min}$ temporal resolution and $60 \mathrm{~m}$ horizontal resolution. The vertical extent of the profiles is determined by the altitudes where the method is applicable, i.e. the atmosphere above the geometrical compression of the ground-based zenith pointing lidar and below the geometrical compression of the nadir-pointing airborne lidar. The essential problem for the proper application of the two-stream method is the requirement that both lidars must sample the same atmosphere. The pre-selection of the appropriate signals can be done using the iterative correlation method (Ritter et al., 2006). Similarly, the two-stream algorithm has a potential to be applied for each of the time periods when the zenith-pointing AMALi crosses the path of the nadirpointing satellite based CALIOP lidar.

\section{Conclusions}

The robust construction and trouble-free operation over the past six years of the AMALi lidar system proved it as an excellent tool for tropospheric airborne and ground based investigations for Arctic studies. The AMALi data obtained with both standard and novel methodology were successfully implemented for several aerosol, cloud and atmospheric dynamics case studies, as mentioned in the introduction, serving a large community of end-users, which are not only "lidarists". The AMALi has successfully been deployed in six airborne field campaigns and is planned to be involved during the upcoming SORPIC (Solar Radiation and Phase Discrimination of Arctic Clouds) in April 2010 and followup campaigns of PAM-ARCMIP (Pan-Arctic Measurements and Arctic Regional Climate Model Intercomparison). The AMALi results were successfully compared with the results of the two AWI ground based lidars, the KARL and the COMCAL, as well as with the in situ instrumentation installed on board of the aircraft for studies involving various cloud systems. To date, the AMALi has not been compared directly to other airborne lidars. However, the technical specifications of the AMALi provide confidence that this system is built optimally for cost, size, safety, performance, and potential to obtain good quality results. For example the AMAli system has quite a large field of view $\left(10^{-3} \mathrm{rad}\right)$ in comparison with other airborne lidars (e.g. $10^{-4} \mathrm{rad}$ of the NASA's CPL), assuring the eye-safety of the low flying nadir-pointing aircraft. Unlike large and complex threewavelength airborne lidars (e.g. the DLR's ALEX) and easily portable but single-wavelength lidars (e.g. the CEA/CNRS's LUAVA) the AMALi utilizes two-wavelengths plus depolarization scheme (with choice of $355 / 532 \mathrm{~nm}$ or $532 / 1064 \mathrm{~nm}$ ) to balance the obtaining of additional information (backscatter ratio, color ratio) and keeping the lidar itself small and compact. Moreover, the modular design of the AMALi optical assembly provides an opportunity to integrate an additional module for the detection of the Raman-shifted wavelength (e.g. $387 \mathrm{~nm}$ for nitrogen) in the future.

In contrast to most of the airborne evaluation approaches, requiring the difficult assessment of the backscatter coefficient calibration value along the flight in the aerosol rich lower troposphere, either by estimating it or by measuring it with additional instrumentation, the iterative calculation of the calibration value described in this paper uses the lidar signal alone. This approach provides calibrated quantitative information on the particle backscatter coefficient, additionally to the qualitative range and background corrected signals provided typically by airborne lidars. The estimate of the calibration value at any time during the flight allowed calculation of the backscatter ratio profiles under clear-sky conditions, with the assumption of a constant lidar ratio of 20-25 sr for clear Arctic air and 30-35 sr for polluted Arctic air. These assumptions were applied to the short range AMALi measurements $(2.7 \mathrm{~km})$ under a very stable Arctic atmosphere with quasi-uniform air mass transport. For flights where the air mass transport was of non-uniform character and the contamination of pollutants was expected at particular altitudes, the height dependent lidar ratio must be assumed. However, the sensitivity studies performed for both types of the retrievals showed no significant disadvantage, i.e. errors in the backscatter coefficient of less than $2.6 \times 10^{-7} \mathrm{~m}^{-1} \mathrm{sr}^{-1}$ were obtained.

\section{Appendix A}

\section{Eye-safety constraints}

To ensure the eye-safety inside the aircraft the AMALi is covered with a sheet-metal box mounted onto the optical assembly. The laser light is sent to the atmosphere through an opening of $15 \mathrm{~cm}(50 \mathrm{~cm})$ diameter in the floor of the Polar 2 (Polar 5) aircraft or through a similar opening in the roof. In the latter case, the laser beam is covered by a light metal tube up to the roof (Fig. 1, middle). Outside the aircraft, a large laser beam divergence ensures that the laser light is eye-safe at distances off the lidar greater than $2.375 \mathrm{~km}$ in the IRVIS and $2.1 \mathrm{~km}$ in the UVVIS configuration. Safe operation of the AMALi is achieved by switching on the laser only after the aircraft reaches the minimal operation height and when the safety shield is locked and fully covers the laser emitting subsystem.

The eye-safety calculations were performed for both configurations according to the Maximum Permissible Exposure 
Table A1. The Maximum Permissible Exposure (MPE) values for the direct exposure of the eye to laser radiation accordingly to the Sicherheitstechnischen Festlegungen für Lasergeräte und Anlagen, VDE-Verlag Beuth 1998, ISSN 0178-224X.

\begin{tabular}{lrrr}
\hline & $\begin{array}{c}\text { Criterion } 1 \\
10^{-9}-10^{-7} \mathrm{~s}\end{array}$ & $\begin{array}{r}\text { Criterion } \\
10^{-3}-10 \mathrm{~s}\end{array}$ & $\begin{array}{c}\text { Criterion 3 } \\
\text { Emission duration }\end{array}$ \\
\hline Wavelength 315-400 nm & $5.6 \times 10^{3} \times t^{0.25} \mathrm{Jm}^{-2}$ & $5.6 \times 10^{3} \times t^{0.25} \mathrm{Jm}^{-2}$ & \\
Wavelength 400-550 nm & $5 \times 10^{-3} \mathrm{Jm}^{-2}$ & $18 \times t^{0,75} \mathrm{Jm}^{-2}$ & $N^{-0.25} \times 5 \times 10^{-3} \mathrm{Jm}^{-2}$ \\
Wavelength $1050-1150 \mathrm{~nm}$ & $5 \times 10^{-2} \mathrm{Jm}^{-2}$ & $90 \times t^{0,75} \mathrm{Jm}^{-2}$ & $N^{-0.25} \times 5 \times 10^{-2} \mathrm{Jm}^{-2}$ \\
\hline
\end{tabular}

(MPE) for direct viewing into the laser beam (SFLA, 1998). Each MPE value of Table A1 depends on the laser specifications given in Table 1.

For the IRVIS configuration infrared and visible pulses are emitted from the aircraft flying at the maximum permissible altitude of $3 \mathrm{~km}$ at the minimal crusing speed of $66 \mathrm{~m} \mathrm{~s}^{-1}$. For this altitude and the laser beam divergence of $2.6 \mathrm{mrad}$ the laser foot-print on the ground/sea expands to $7.8 \mathrm{~m} \mathrm{di-}$ ameter and covers a surface of $47.78 \mathrm{~m}^{2}$. For the laser repetition rate of $15 \mathrm{~Hz}$ the centres of the two following laserfootprints are separated from each other by $4.4 \mathrm{~m}$ on the ground. Hence, a motionless observer can look into 2 consecutive laser pulses at most.

The exposure effect of $1064 \mathrm{~nm}$ and $532 \mathrm{~nm}$ pulses is additive and the actual exposure for both wavelengths must remain below the MPE value and satisfy all following criteria:

1. The exposure to one single pulse in the pulse-sequence cannot exceed the MPE value calculated for the direct exposure of the eye to the laser pulse. The $\mathrm{MPE}_{532}^{1}=5 \times 10^{-3} \mathrm{Jm}^{-2}$ and $\mathrm{MPE}_{1064}^{1}=50 \times 10^{-3} \mathrm{Jm}^{-2}$. The actual exposure for a $532 \mathrm{~nm}$ pulse with energy of $120 \mathrm{~mJ}$ is $E_{532}^{1}=2.5 \times 10^{-3} \mathrm{Jm}^{-2}$, and for a $1064 \mathrm{~nm}$ pulse with energy of $60 \mathrm{~mJ}$ is $E_{1064}^{1}=1.26 \times 10^{-3} \mathrm{Jm}^{-2}$. The quotients of the actual exposure and the MPE values are 0.5 for $532 \mathrm{~nm}$ and 0.025 for $1064 \mathrm{~nm}$.

2. The mean exposure to the duration of the pulsesequence cannot exceed the MPE value for a pulsesequence duration. For exposure duration $t$ of $0.13 \mathrm{~s}$ ( 2 pulses at $15 \mathrm{~Hz}$ ) the $\mathrm{MPE}_{532}^{2}=3.97 \mathrm{Jm}^{-2}$ and $\mathrm{MPE}_{1064}^{2}=19,48 \mathrm{Jm}^{-2}$. The actual exposure averaged for pulse-sequence is $E_{532}^{2}=2.51 \times 10^{-3} \mathrm{Jm}^{-2}$ and $E^{2}{ }_{1064}=1.26 \times 10^{-3} \mathrm{Jm}^{-2}$. The quotients of the MPE and the actual exposure are $0.63 \times 10^{-3}$ for $532 \mathrm{~nm}$ and $0.06 \times 10^{-3}$ for $1064 \mathrm{~nm}$.

3. The exposure to one single pulse in the pulsesequence cannot exceed the MPE value calculated for the first criteria multiplied by the correction factor $N^{-0.25}$, where $N$ is number of the pulses in the pulse-sequence. Hence, the $\mathrm{MPE}_{532}^{3}=4.2 \times 10^{-3} \mathrm{Jm}^{-2}$ and $\mathrm{MPE}_{1064}^{3}=42 \times 10^{-3} \mathrm{Jm}^{-2}$. The actual exposure is $E_{532}^{3}=2.5 \times 10^{-3} \mathrm{Jm}^{-2}$ and $E_{1064}^{3}=1.26 \times 10^{-3} \mathrm{Jm}^{-2}$. The quotients of the MPE and the actual exposure are 0.595 for $532 \mathrm{~nm}$ and 0.03 for $1064 \mathrm{~nm}$, respectively.

For each criterion the sum of the quotients from both wavelengths is less than 1 and the eye-safety criteria are passed. The quotient value obtained for the third criterion is the highest and constrains the AMALi operation. To calculate the minimum permissible height for the eye-safe measurement the maximum permissible altitude is multiplied by the square root of the final quotient of the third criterion (0.625), as the exposure intensity is proportional to $r^{-2}$. Hence, the minimum permissible flight altitude for eye-safe operation of AMALi in the nadir-pointing IRVIS configuration is $2372 \mathrm{~m}$.

For the UVVIS configuration, ultraviolet and visible pulses are emitted. For $355 \mathrm{~nm}$, the MPE is higher than for $532 \mathrm{~nm}$, as the eye is less sensitive in the UV spectrum, and for the simultaneous exposure the MPE values are not treated additively. The exposure is calculated as described for the IRVIS configuration. The exposure of one UV pulse with energy of $25 \mathrm{~mJ}$ results in $1.57 \times 10^{-3} \mathrm{Jm}^{-2}$ and the averaged exposure is 3 orders of magnitude below the MPE value. Hence, the limitation of operating altitude in UVVIS nadirpointing configuration results only from eye safety considerations of the VIS wavelength. Again, the third criterion is limiting for the eye safety and leads to a minimum flight altitude of $2070 \mathrm{~m}$.

Acknowledgements. The authors would like to thank the four anonymous referees and Robyn Schofield who helped us to improve this manuscript with their valuable comments and contributions.

Edited by: A. Minikin

\section{References}

Alvarez, J. M., Vaughan, M. A., Hostetler, C. A., Hunt, W. H. and Winker, D. M.: Calibration technique for polarization-sensitive lidars. J. Atmos. Ocean. Technol., 23, 683-699, 2006.

Ansmann, A., Riebesell, M., and Weitkamp, C.: Measurements of aerosol profiles with Raman lidar, Opt. Lett., 15, 746-748, 1990. 
Ansmann, A., Wandinger, U., Riebesell, M., Weitkamp, C., and Michaelis, W.: Independent measurements of extinction and backscatter profiles in cirrus clouds by using a combined Raman elastic-backscatter Lidar, Appl. Opt., 31, 7113-7131, 1992.

Behrendt, A. and Nakamura, T.: Calculation of the calibration constant of polarization lidar and its dependency on atmospheric temperature, Opt. Express, 10, 805-817, 2002.

Biele, J., Beyerle, G., and Baumgarten, G.: Polarization lidar: Corrections of instrumental effects, Optics Express, 7(12), 427-435, 2000.

Chazette, P., Sanak, J., and Dulac, F.: New approach for aerosol profiling with a lidar on board an ultralight aircraft: application to the African monsoon, Multidiscipl. Anal. Environ. Sci. Technol., 41, 8335-8341, 2007.

Chazette, P., Sanak, J., Raut, J.-C., and Berthier, S.: Mini-lidar for balloon-borne and aircraft-borne measurements, 24st International Laser Radar Conference (ILRC24), 23-27 June 2008, Boulder, CA, USA, 2008.

Chen, W., Chiang, C., and Nee, J.: Lidar Ratio and Depolarization Ratio for Cirrus Clouds, Appl. Optics, 41, 6470-6476, 2002.

Cuesta, J. and Flamant, P. H.: Two-Stream lidar inversion algorithm for airborne and satellite validations, in Proceedings of 22nd International Laser Radar Conference (ILRC 2004), edited by: Pappalardo, G., and Amodeo, A., ESA SP-561, 1, 471-474, 2004.

Cuesta, J., Chazette, P., Sanak, J., Allouis, T., Durrieu, S., Genau, P., Flamant, C., and Flamant, P. H.: New airborne lidar observes forest canopies, SPIE Newsroom, doi:10.1117/2.1200909.1732, 2009.

Dethloff, K., Rinke, A., Lehmann, R., Christensen, J.H., Botzet, M., and Machenhauer, B.: Regional climate model of the Arctic atmosphere, J. Geophys. Res., 101(D8), 23401-23422, 1996.

Dörnbrack, A., Stachlewska, I. S., Ritter, C., and Neuber, R.: Aerosol distribution around Svalbard during intense easterly winds, Atmos. Chem. Phys., 10, 1473-1490, 2010, http://www.atmos-chem-phys.net/10/1473/2010/.

Ehrlich, A., Bierwirth, E., Wendisch, M., Gayet, J.-F., Mioche, G., Lampert, A., and Heintzenberg, J.: Cloud phase identification of Arctic boundary-layer clouds from airborne spectral reflection measurements: test of three approaches, Atmos. Chem. Phys., 8, 7493-7505, 2008, http://www.atmos-chem-phys.net/8/7493/2008/.

Fernald, F. G.: Analysis of atmospheric lidar observations: some comments, Appl. Opt., 23, 652-653, 1984.

Flamant, C., Pelon, J., Chazette, P., Trouillet, V., Quinn, P., Frouin, R., Bruneau, D., Leon, J.-F., Bates, T., Johnson, J., and Livingstone, T.: Airborne lidar measurements of aerosol spatial distribution and optical properties over the Atlantic Ocean during a European pollution outbreak of ACE-2, Tellus, 52B, 662-677, 2000.

Freudenthaler, V., Esselborn, M., Wiegner, M., Heese, B., Tesche, M., Ansmann, A., Müller, D., Althausen, D., Wirth, M., Fix, A., Ehret, G., Knipperts, P., Toledano, C., Gasteiger, J., Garhammer, M, and Seefeldner, M.: Depolarization-ratio profiling at several wavelengths in pure Saharan dust during SAMUM, Tellus 61B, 165-179, 2009.

Gimmestad, G. G.: Reexamination of depolarization in lidar measurements, Appl. Opt. 47, 3795-3802, 2008.

Gayet, J.-F., Stachlewska, I. S., Jourdan, O., Shcherbakov, V.,
Schwarzenboeck, A., and Neuber, R.: Microphysical and optical properties of precipitating drizzle and ice particles obtained from alternated lidar and in situ measurements, Ann. Geophys., 25, 1487-1497, 2007,

http://www.ann-geophys.net/25/1487/2007/.

Goodman, J. W.: Statistical Optics, J. Wiley \& Sons, 1985.

Hughes, H. G. and Paulson, M. R.: Double-ended lidar techniques for aerosol studies, App. Opt., 27, 2273-2278, 1988.

Heese, B., Freudenthaler, V., Seefeldner, M., and Wiegner, M.: POLIS - A new POrtable LIdar System for ground-based and airborne measurements of aerosols and clouds, Proceedings of the International Laser Radar Conference, Quebec, Canada, 1, 7174, 2002.

Heese, B., Freudenthaler, V., Seefeldner, M., and Wiegner, M.: First results from the portable lidar system POLIS, Proceedings of the International Laser Radar Conference, Matera, Italy, 1, 79-82, 2004.

Immler, F., Beninga, I., Ruhe, W., Stein, B., Mielke, B., Rutz, S., Terli, Ö., and Schrems, O.: A new lidar system for the detection of cloud and aerosol backscatter, depolarization, extinction and fluorescence, Reviewed and Revised Papers Presented at the 23rd International Laser Radar Conference (ILRC 2006), 1, 35-38, 2006.

Klett, J. D.: Stable analytical inversion solution for processing lidar returns, Appl. Opt., 20, 211-220, 1981.

Klett, J. D.: Lidar inversions with variable backscatter/extinction values, Appl. Opt., 24, 211-220, 1985.

Kovalev, V. A. and Eichinger, W. E.: Elastic Lidar: Theory, Practice, and Analysis Methods, J. Wiley \& Sons, ISBN 0-47120171-5, 2004.

Kunz, G. J.: Bipath Method as a way to measure the spatial backscatter and extinction coefficients with lidar, App. Opt., 26, 794-795, 1987.

Kunz, G. J. and de Leeuw, G.: Inversion of lidar signals with the slope method, Appl. Opt. 32, 3249-3256, 1993.

Lampert, A., Ehrlich, A., Dörnbrack, A., Jourdan, O., Gayet, J.F., Mioche, G., Shcherbakov, V., Ritter, C., and Wendisch, M.: Microphysical and radiative characterization of a subvisible midlevel Arctic ice cloud by airborne observations - a case study, Atmos. Chem. Phys., 9, 2647-2661, 2009, http://www.atmos-chem-phys.net/9/2647/2009/.

Lampert, A., Ritter, C., Hoffmann, A., Gayet, J.-F., Mioche, G., Ehrlich, A., Dörnbrack, A., Wendisch, M., and Shiobara, M.: Lidar characterization of the Arctic atmosphere during ASTAR 2007: four cases studies of boundary layer, mixed-phase and multi-layer clouds, Atmos. Chem. Phys., 10, 2847-2866, 2010

Matthias, V., Freudenthaler, V., Amodeo, A., Balin, I., Balis, D., Bösenberg, J., Chaikovsky, A., Chourdakis, G., Comeron, A., Delaval, A., De Tomasi, F., Eixmann, R., Hågård, A., Komguem, L., Kreipl, S., Matthey, S., Rizi, V., Rodrigues, J. A., Wandinger, U., and Wang X.: Aerosol lidar intercomparison in the framework of the EARLINET project. 1. Instruments, Appl. Opt., 43, 961-976, 2004.

McGill, M., Hlavka, D., Hart, W., Scott, V. S., Spinhirne, J., and Schmid, B.: Cloud Physics Lidar: instrument description and initial measurement results, App. Opt., 41(18), 3725-3734, 2002.

McGill, M. J., Hlavka, D. L., Hart, W. D., Welton, E. J., and Campbell, J. R.: Airborne lidar measurements of aerosol optical properties during SAFARI-2000, J. Geophys. Res., 108(D13), 8493, 
doi:10.1029/2002JD002370, 2003.

Moerl, P., Reinhardt, M. E., Renger, W., and Schellhase, R.: The use of the airborne lidar ALEX-F for aerosol tracing in the lower troposphere, Contr. Atmas. Phys., 45, 403-410, 1981.

Pahlow, M., Kovalev, V. A., and Parlange, M. B.: Calibration Method for Multiangle Lidar Measurements Appl. Opt. 43, 2948-2956, 2004.

Reichardt, J., Baumgart, R., and McGee, T. J.: Three-signal method for accurate measurements of depolarization ratio with lidar, Appl. Opt. 42, 4909-4913, 2003.

Renger, W., Kiemle, C., Schreiber, H. G., Wirth, M., and Mörl, P.: Correlative measurements in support of LITE using the airborne backscatter lidar ALEX, in: Advances in Atmospheric Remote Sensing with Lidar, edited by: Ansmann, A., Neuber, R., Rairoux, P., and Wandinger, U., Springer-Verlag, Berlin, 165168, 1997.

Richter, A., Gayet, J.-F., Mioche, G., Ehrlich, A., and Dörnbrack, A.: Mixed-Phase Clouds in the Arctic, a Synopsis of Airborne Lidar, in-Situ, and Albedometer Observations, complemented by Meteorological Analyses, in: Proceedings of 24th International Laser Radar Conference (ILRC 2008), 2, 881-884, 2008.

Rinke, A., Dethloff, K., and Fortmann, M.: Regional climate effects of Arctic Haze, Geophys. Res. Lett., 31(16), L16202, doi:10.1029/2004GL020318, 2004.

Ritter, C., Kirsche, A., and Neuber, R.: Tropospheric Aerosol Characterized by a Raman Lidar over Spitsbergen, in: Proceedings of 22nd International Laser Radar Conference (ILRC 2004), edited by: Pappalardo, G. and Amodeo, A., ESA SP-561, 1, 459-462, 2004.

Ritter, C., Stachlewska, I. S., and Neuber, R.: Application of the two-stream evaluation for a case study of Arctic Haze over Spitsbergen, in: Proceedings of 23nd International Laser Radar Conference (ILRC 2006), edited by: Nagasawa, C. and Sugimoto, N., ISBN 4-9902916-0-3, 1, 507-510, 2006.

Ritter, C., Hoffmann, A., Osterloh, L., and Bckmann, C.: Estimation of the Liquid Water Content of a low level Arctic winter cloud, in: Proceedings of 43nd International Laser Radar Conference (ILRC 2008), 1, 597-582, 2008.

Sasano, Y., Browell, E. V., and Ismail, S.: Error caused by using a constant extinction/backscattering ratio in the lidar solution, Appl. Opt., 24, 3929-3932, 1985.

Sicard, M., Chazette, P., Pelon, J., Won, J. G., and Yoon, S.-C.: Variational Method for the Retrieval of the Optical Thickness and the Backscatter Coefficient from Multiangle Lidar Profiles Appl. Opt., 41, 493-502, 2002.

Shimoda, K.: Introduction to Laser Physics, Springer-Verlag Berlin Heidelberg, 1986.

Shipley, S. T., Tracy, D. H., Eloranta, E. W., Trauger, J. T., Sroga, J. T., Roesler, F. L., and Weinman, J. A.: A High Spectral Resolution Lidar to measure optical scattering properties of atmospheric aerosols, Part I: Instrumentation and theory, Appl. Opt., 23, 3716-3724, 1983.
Sicherheitstechnische Festlegungen für Lasergeräte und Anlagen, VDE-Verlag Beuth, ISSN 0178-224X, 1998.

Stachlewska, I. S., Wehrle, G., Stein, B., and Neuber, R.: Airborne Mobile Aerosol Lidar for measurements of Arctic aerosols, in: Proceedings of 22nd International Laser Radar Conference (ILRC 2004), edited by: Pappalardo, G. and Amodeo, A., ESA SP-561, 1, 87-89, 2004.

Stachlewska, I. S., Ritter, C., and Neuber, R.: Application of the two-stream inversion algorithm for retrieval of extinction, backscatter and lidar ratio for clean and polluted Arctic air, in: Proceedings of SPIE, 5584, 03/1-03/8, 2005.

Stachlewska, I. S. and Dörnbrack, A.: Application of iterative airborne lidar inversion and its interpretation by means of ECMWF operational analyses, in: Reviewed and Revised Papers Presented at the 23rd International Laser Radar Conference (ILRC 2006), 1, 471-474, $2006 a$.

Stachlewska, I. S.: Investigation of tropospheric arctic aerosol and mixed-phase clouds using airborne lidar technique, $\mathrm{PhD}$ Thesis, University of Potsdam, opus.kobv.de/ubp/volltexte/2006/698/, 2006b.

Stachlewska, I. S., Gayet, J.-F., Duroure, C., Schwarzenboeck, A., Jourdan, O., Shcherbakov, V., and Neuber, R.: Observations of mixed-phase clouds using airborne lidar and in-situ instrumentation, in: Reviewed and Revised Papers Presented at the 23rd International Laser Radar Conference (ILRC 2006), 1, 325-328, 2006c.

Stachlewska, I. S. and Ritter, C.: On retrieval of lidar extinction profiles using Two-Stream and Raman techniques, Atmos. Chem. Phys., 10, 2813-2824, 2010, http://www.atmos-chem-phys.net/10/2813/2010/.

Treffeisen, R., Herber, A., Ström, J., Shiobara, M., Yamanouchi, T., Yamagata, S., Holmen, K., Kriews, M., and Schrems, O.: Interpretation of Arctic Aerosol Properties using Cluster Analysis applied to observations in the Svalbard Area, Tellus, 56B(5), 457-476, 2004.

Wang, X., Frontoso, M. G., Pisani, G., and Spinelli, N.: Retrieval of atmospheric particles optical properties by combining groundbased and spaceborne lidar elastic scattering profiles, Opt. Express, 15, 6734-6743, 2007.

Winker, D. M., Hunt, B. H., and McGill, M. J.: Initial performance assessment of CALIOP, Geophys. Res. Lett., 34, L19803, doi:10.1029/2007GL030135, 2007.

Yamanouchi, T., Treffeisen, R., Herber, A., Shiobara, M., Yamagata, S., Hara, K., Sato, K., Yabuki, M., Tomikawa, Y., Rinke, A., Neuber, R., Schumacher, R., Kriews, M., Ström, J., Schrems, O., and Gernandt, H.: Arctic Study of Tropospheric Aerosol and Radiation (ASTAR) 2000: Arctic haze case study, Tellus, 57B, 141-152, 2005. 